\title{
En route to photoaffinity labeling of the bacterial lectin FimH
}

\author{
Thisbe K. Lindhorst ${ }^{* 1}$, Michaela Märten ${ }^{1}$, Andreas Fuchs ${ }^{1}$ \\ and Stefan D. Knight ${ }^{2}$
}

\section{Full Research Paper}

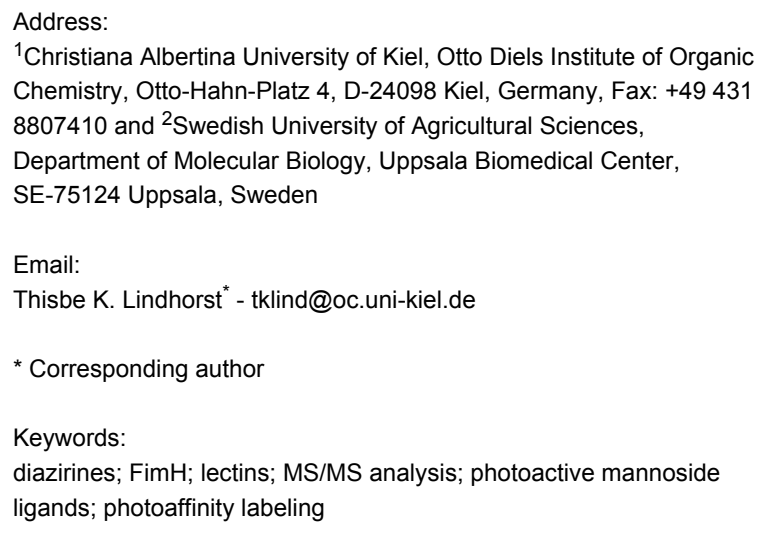

${ }^{1}$ Christiana Albertina University of Kiel, Otto Diels Institute of Organic Chemistry, Otto-Hahn-Platz 4, D-24098 Kiel, Germany, Fax: +49 431 8807410 and ${ }^{2}$ Swedish University of Agricultural Sciences, Department of Molecular Biology, Uppsala Biomedical Center, SE-75124 Uppsala, Sweden

Email:

Thisbe K. Lindhorst ${ }^{*}$ - tklind@oc.uni-kiel.de

* Corresponding author

Keywords:

diazirines; FimH; lectins; MS/MS analysis; photoactive mannoside ligands; photoaffinity labeling

Beilstein J. Org. Chem. 2010, 6, 810-822. doi:10.3762/bjoc.6.91

Received: 20 May 2010

Accepted: 21 July 2010

Published: 26 August 2010

Editor-in-Chief: J. Clayden

(C) 2010 Lindhorst et al; licensee Beilstein-Institut. License and terms: see end of document.

\begin{abstract}
\section{Introduction}

Photoaffinity labeling is a technique by which ligand binding sites of a receptor protein can be identified in solution. It requires a photoactive ligand derivative, which can form a reactive species upon photo-excitation. Thus, incubation of the photoprobe with a protein followed by irradiation can result in a photo-crosslinked product, that provides structural information on the binding site of the protein (Figure 1) [1].
\end{abstract}

Mannose-specific adhesion of Escherichia coli bacteria to cell surfaces, the cause of various infections, is mediated by a fimbrial lectin, called FimH. X-ray studies have revealed a carbohydrate recognition domain (CRD) on FimH that can complex $\alpha$-D-mannosides. However, as the precise nature of the ligand-receptor interactions in mannose-specific adhesion is not yet fully understood, it is of interest to identify carbohydrate recognition domains on the fimbrial lectin also in solution. Photoaffinity labeling serves as an appropriate methodology in this endeavour and hence biotin-labeled photoactive mannosides were designed and synthesized for photoaffinity labeling of FimH. So far, the photo-crosslinking properties of the new photoactive mannosides could be detailed with the peptide angiotensin II and labeling of FimH was shown both by MS/MS studies and by affino dot-blot analysis.
It has become our goal to utilize this methodology for the investigation of carbohydrate binding of the bacterial lectin FimH. The protein FimH is found on the tips of type 1 fimbriae, long adhesive filamentous appendages on the surface of many bacteria, such as Escherichia coli [2-5]. In X-ray studies a carbohydrate recognition domain (CRD), which can complex one $\alpha$-D-mannosyl residue, has been clearly identified [6-8]. 


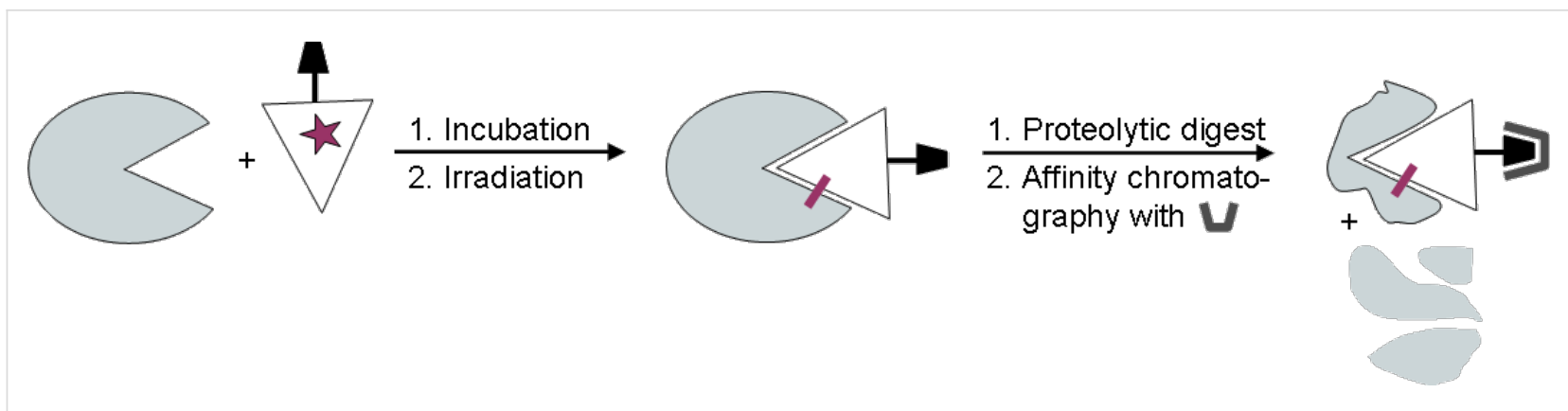

Figure 1: The photoaffinity technique allows the identification of ligand binding sites of a receptor protein after photo-crosslinking, proteolysis and affinity chromatography.

However, other binding experiments performed with a multitude of synthetic as well as natural mannosides and oligomannosides are not in complete agreement with just one monovalent carbohydrate binding site on the FimH protein [9-13] Thus, we decided to employ photoactive ligands to probe carbohydrate binding to the known CRD in solution and to identify possibly auxiliary, so far unknown, binding sites on bacterial lectin FimH [2].

The known FimH CRD was taken as the lead structure for the design of an appropriate photoactive ligand. Inspection of the available $\mathrm{X}$-ray data clearly shows that $\alpha$-D-mannosides are complexed in the CRD with the aglycone moiety sticking out of the binding pocket. The entrance of the CRD is flanked by the tyrosine residues Tyr48 and Tyr137 ('tyrosine gate') that can form favorable interactions with appropriate mannosidic aglycone moieties, such as $\pi$ - $\pi$-stacking with the phenyl group of benzyl mannosides [14]. In a preceding work, we synthesized the three corresponding photoactive $\alpha$-D-mannosides, 1,2 , and 3 (Figure 2a) for photolabeling of the bacterial lectin FimH [15]. They differ in their photoactive functional groups, which are part of the aglycone moiety. Upon irradiation, the aryl azide $\mathbf{1}$ and the diazirine $\mathbf{2}$ expel nitrogen to yield a reactive nitrene and a carbene intermediate, respectively. Irradiation of the benzophenone $\mathbf{3}$, on the other hand, delivers a reactive triplet diradical. a)<smiles>Nc1c(F)c(F)c(COC2C3C(O)C(O)C(O)C(O)(C2O)C3O)c(F)c1F</smiles>
1

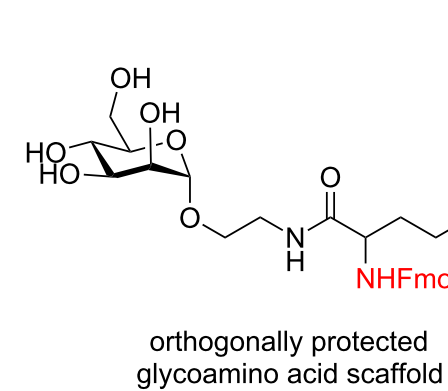

4<smiles>OCC1(O)C(O)C2C(O)C(OCc3ccc(C4(C(F)(F)F)N=N4)cc3)C1C2(F)F</smiles>

2

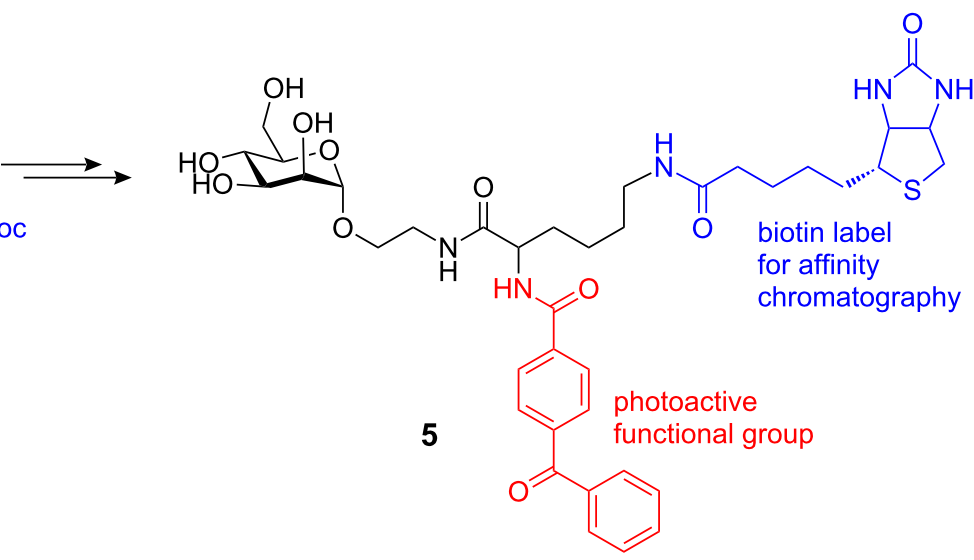

Figure 2: a) Three known photolabile $\alpha$-D-mannosides that differ in the nature of the photoactive functional group (in red); b) the known bifunctional mannoside ligand $\mathbf{5}$ is based on the orthogonally protected glycoamino acid $\mathbf{4}$ and well suited for photoaffinity labeling. 
In addition, in order to combine a photoactive functional group with an affinity label within the same mannoside, the orthogonally protected glycoamino acid scaffold 4 was synthesized and used for the preparation of the biotin-labeled photophore $\mathbf{5}$, which is well suited for the streptavidine-based photoaffinity labeling, relying on the extraordinary high affinity of the protein streptavidine for biotin (Figure 2b) [16].

\section{Results and Discussion}

In order to learn more about the ligand properties of the previously prepared photoactive mannosides $\mathbf{1}, \mathbf{2}, \mathbf{3}$, and $\mathbf{5}$, we have performed computer-aided docking studies using FlexX [17-19] to get an idea about their binding to the bacterial lectin FimH, as reported earlier [20]. FlexX produces so-called scoring values for each docked ligand, which can be regarded as a rough estimate of its free binding energy. Low (more negative) scores correlate with high affinities, whilst higher scores reflect diminished binding potency (Table 1). Docking was based on two different X-ray structures. In the first case, crystals with an open tyrosine gate were taken as the basis [7], whilst in the second case, a closed-gate conformation of FimH was used for the modeling [8]. This led to somewhat different predictions, as expected, however, the same trends were revealed for ligands 1-3 and $\mathbf{5}$ in comparison with the wellknown standard ligands methyl $\alpha$-D-mannoside (MeMan) and $p$-nitrophenyl $\alpha$-D-mannoside (pNPMan), respectively (Table 1).

When these mannosides were tested as inhibitors of type 1 fimbriae-mediated bacterial adhesion to a mannan-coated surface in an ELISA [21,22], $\mathrm{IC}_{50}$-values were obtained, which reflect the concentration of the derivative employed, that leads to $50 \%$ inhibition of bacterial adhesion. Three independent measurements resulted in high standard deviations, a typical characteristic of this assay, whereas the relative trend in a series of tested ligands can be verified with high reproducibility. Hence, the inhibitory potencies of the tested ligands were referenced to an internal standard inhibitor, MeMan (inhibitory potency $\equiv 1$ ), to deduce relative inhibitory potencies, so-called RIP-values (Table 1). This uniform referencing shows, that all photoactive mannosides surpass the inhibitory potency of MeMan, and that mannosides $\mathbf{1}$ and $\mathbf{2}$ are more powerful inhibitors than $\mathbf{3}$ and $\mathbf{5}$. Consequently, the synthetic photoactive mannosides are suited as ligands for the bacterial lectin FimH. Comparison of the measured $\mathrm{IC}_{50}$-values with the theoretical docking results, discloses a somewhat limited value of the computer-aided predictions in this case. Docking suggested that mannosides 2, 3 and $\mathbf{5}$ are the most potent ligands of FimH in the tested series, which was not confirmed experimentally. On the other hand, it has to be kept in mind that the employed ELISA is not based on pure FimH, but rather on type 1-fimbriated bacteria, a dissimilar more complex system.

The binding studies showed that mannosides with a typical photolabel in the aglycone moiety serve as ligands for FimH, and that even the more complex glycoamino acid derivative $\mathbf{5}$ is a suitable ligand. Encouraged by these results, we set out to improve the photochemical properties of $\mathbf{5}$ in order to facilitate later photoaffinity-labeling of FimH. Our earlier work suggested that diazirines are more useful photoactive groups than aryl azides and benzophenones [15]. Therefore, the synthesis of a biotin-labeled daizirine-functionalized mannoside was our next target. In this synthesis, aspartic acid was utilized as the scaffold molecule in two different ways in order to allow fine-tuning of the spacing between the mannoside ligand and the photoactive group. Thus, the amino acid derivatives FmocAsp-O $t \mathrm{Bu}$ and Fmoc-Asp $(\mathrm{O} t \mathrm{Bu})-\mathrm{OH}$ were employed in two analogous synthetic pathways, starting with peptide coupling to the known 2-aminoethyl mannoside 6 (Scheme 1) [23]. This led

Table 1: Binding of mannoside ligands to FimH was predicted by computer-aided docking (FlexX) and measured by ELISA utilizing type 1-fimbriated E. coli. $\mathrm{IC}_{50}$-values are averaged from three independent experiments.

\begin{tabular}{|c|c|c|c|c|}
\hline mannoside & $\begin{array}{l}\text { FlexX Scores } \\
\text { "open-gate"a }\end{array}$ & $\begin{array}{l}\text { FlexX Scores } \\
\text { "closed-gate"b }\end{array}$ & $\begin{array}{c}\mathrm{IC}_{50}(\mathrm{SD})^{\mathrm{C}} \\
\text { [mmolar] }\end{array}$ & $\mathrm{RIP}^{\mathrm{d}}$ \\
\hline MeMan & -22.5 & -23.3 & $1.84(1.32)$ & 1 \\
\hline pNPMan & -24.9 & -27.4 & $0.04(0.01)$ & 46 \\
\hline 1 & -23.6 & -24.0 & $0.06(0.01)$ & 31 \\
\hline 2 & $-28.3^{e}$ & $-29.3^{e}$ & $0.12(0.09)$ & 15 \\
\hline 3 & -30.2 & -29.8 & $0.20(0.10)$ & 9 \\
\hline 5 & -31.9 & -36.0 & $0.63(0.42)$ & 3 \\
\hline
\end{tabular}

abased on open-gate structure of FimH, PDB ID: 1KLF [7]

b based on closed-gate structure of FimH, PDB ID: 1UWF [8].

'SD: standard deviation.

${ }^{\mathrm{d}} \mathrm{RIP}$ : relative inhibitory potency.

eTo facilitate docking, the diazirine ring was substituted by a cyclopropyl ring. 


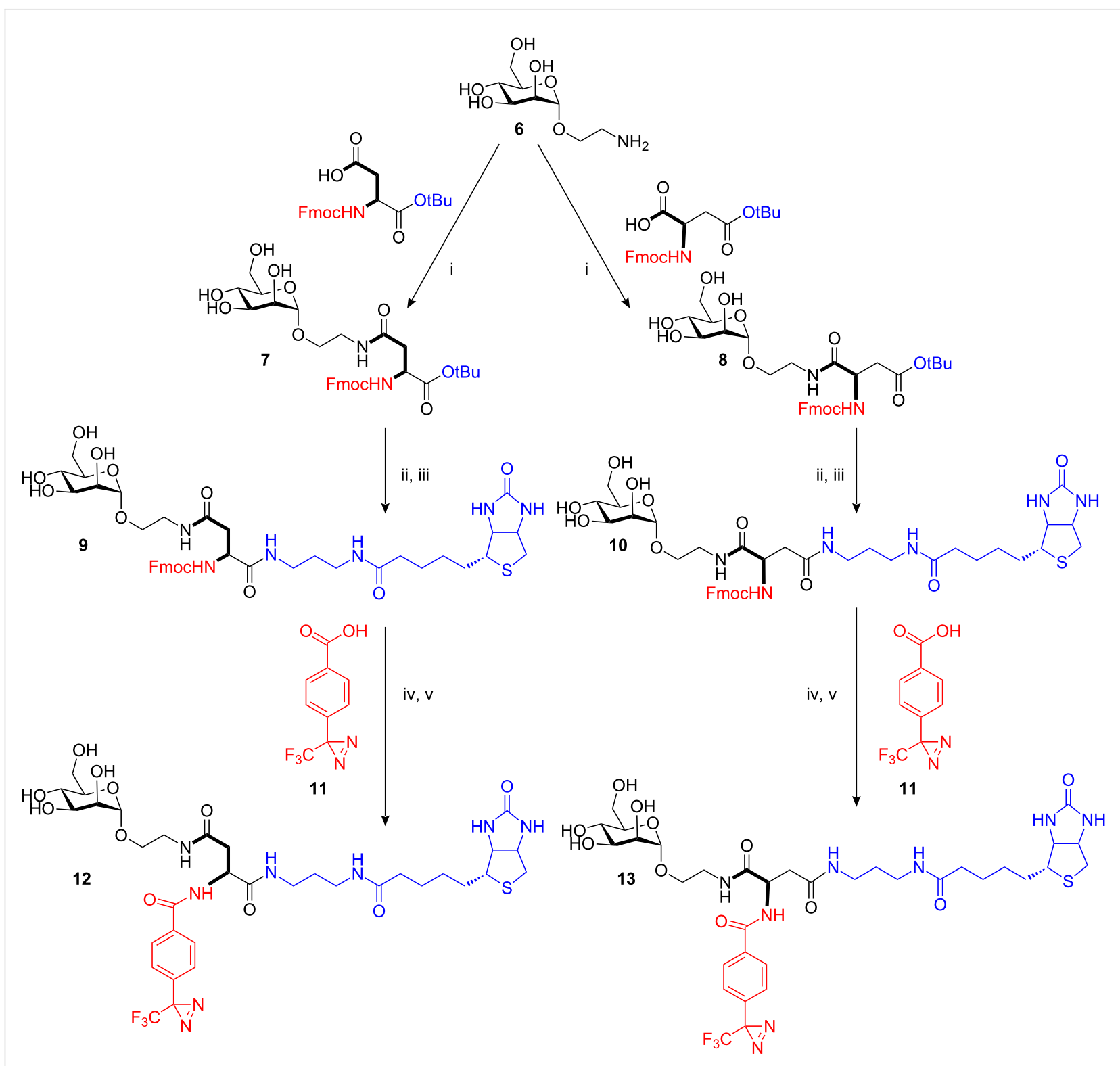

Scheme 1: Synthesis of photoactive glycoamino acids 11 and 12. i) Fmoc-Asp-OtBu (for 7), Fmoc-Asp(OtBu)-OH (for 8), HATU, DIPEA, dry DMF, $\mathrm{N}_{2}, \mathrm{RT}, 95 \%$ for 7 and $96 \%$ for 8 ; ii) $80 \%$ aq TFA, RT; iii) (+)-biotinylamidopropylammonium trifluoroacetate, HATU, DIPEA, dry DMF, N2, RT, $48 \%$ (two steps) for 9 and 26\% (two steps) for 10; (iv) 20\% piperidine, dry DMF, RT; v) HATU, DIPEA, dry DMF, Ar, RT, $81 \%$ (two steps) for 12 and $98 \%$ (two steps) for 13.

to the orthogonally protected mannoside amino acid tert-butyl esters 7 and $\mathbf{8}$. The tert-butyl ester groups were then cleaved under acidic conditions and the resulting acids ligated with the biotin derivative biotinylamidopropylammonium trifluoroacetate. These two steps gave the Fmoc-protected biotin-labeled glycoamino acids $\mathbf{9}$ and 10, respectively. Fmoc-cleavage and peptide coupling with the diazirine $\mathbf{1 1}$ led to the target molecules $\mathbf{1 2}$ and $\mathbf{1 3}$ in good yield.

To test the prepared photoactive mannosides in crosslinking reactions, the model peptide angiotensin II (DRVYIHPF) was first employed. It was irradiated with the three different diazirine-functionalized mannosides 2, 12, and 13. From our earlier work [15] it was known that irradiation of the diazirinefunctionalized mannoside $\mathbf{2}$ with angiotensin II led to a photocrosslinked product with $m / z=698.82$. This double positively charged ion correlates with a 1:1-photoaddition product of peptide and photolabel with the molecular formula $\mathrm{C}_{65} \mathrm{H}_{90} \mathrm{~F}_{3} \mathrm{~N}_{13} \mathrm{O}_{18}{ }^{2+}$ and a monoisotopic mass of 1397.47 Da. We have now carried out MS/MS experiments to analyze the structure of this photo-crosslinked adduct and unequivocally shown that insertion of the carbene, which results after irradi- 
ation of $\mathbf{2}$, occurs at the hydroxyl group in the side chain of the angiotensin tyrosine ( $\mathrm{Y}$ ) (see Experimental Part). This crosslinking reaction leads to the ether $\mathbf{1 4}$ (Scheme 2). Analogously, the photo-crosslinked products, obtained from irradiation of angiotensin II with either $\mathbf{1 2}$ or $\mathbf{1 3}$, can be correlated with the structures of $\mathbf{1 5}$ and $\mathbf{1 6}$, respectively, both showing a peak at $m / z=1851.1$ in their mass spectra, corresponding to a molecular formula of $\mathrm{C}_{84} \mathrm{H}_{11} \mathrm{~F}_{3} \mathrm{~N}_{19} \mathrm{O}_{23} \mathrm{~S}^{+}$(monoisotopic mass $\mathrm{M}=1850.84 \mathrm{Da})$.
The photo-crosslinking experiments with angiotensin II demonstrated, that the synthesized diazirines are well suited as photoprobes for the labeling of this peptide, with a preference for the tyrosine side chain. Thus, the photoactive mannosides were next investigated with the bacterial lectin FimH. For the irradiation experiments a FimH truncate, $\mathrm{FimH}_{\text {tr }}$, which resembles the adhesin domain of the complete FimH, was used [24]. FimH $\mathrm{Fr}_{\mathrm{tr}}$ comprises of amino acids 1-160 of FimH and is terminated by a histidine tag $\mathrm{His}_{6}$. FimH $\mathrm{Fr}_{\text {tr }}$ has the same carbohydrate binding

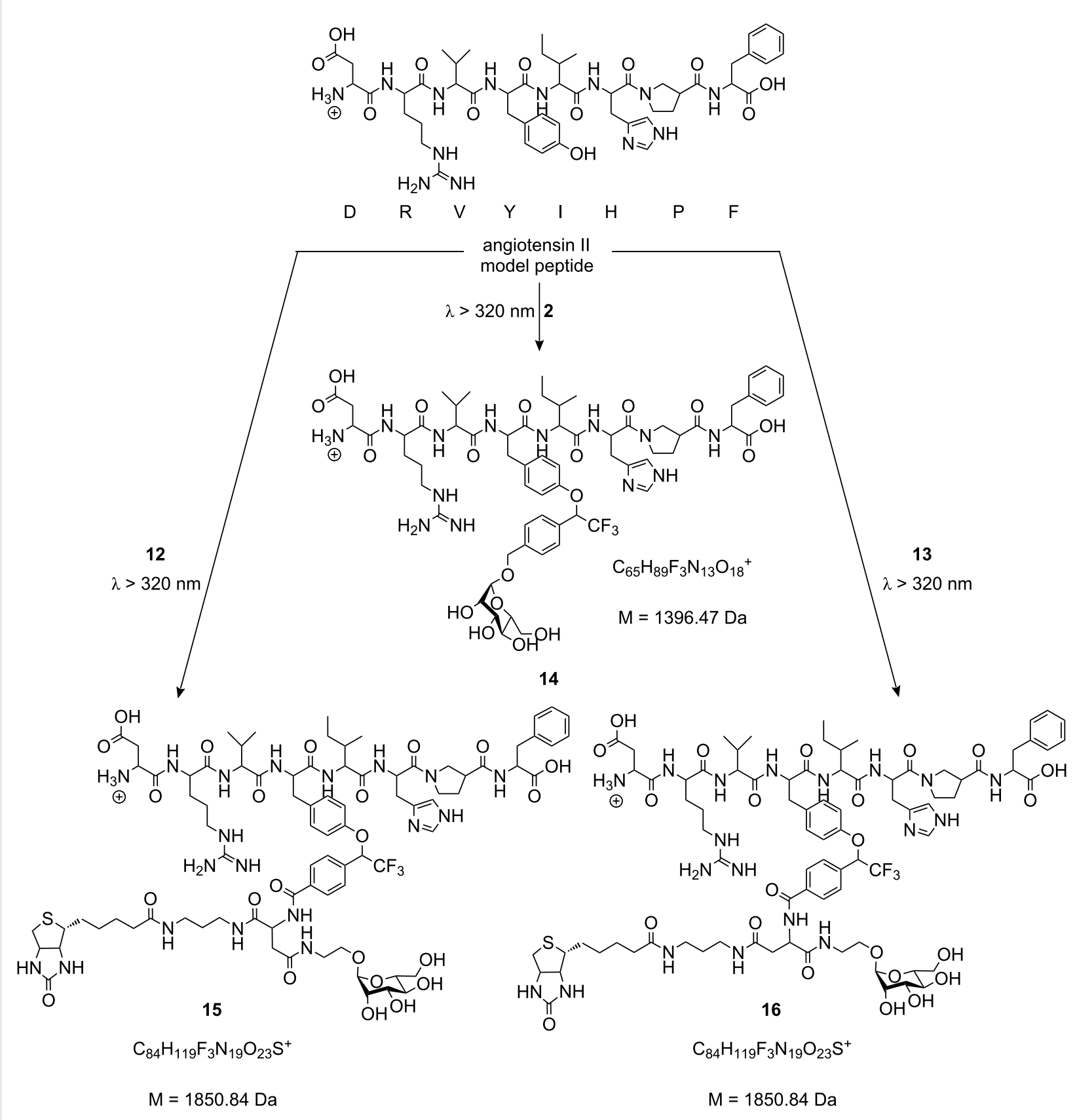

Scheme 2: Photo-crosslinking experiments with the model peptide angiotensin II and the photoactive mannosides 2,12 , and 13 , respectively (see Experimental Part). 
properties as FimH. Mass spectrometric analysis of $\mathrm{FimH}_{\mathrm{tr}}$ revealed $m / z=17839$ (calcd. $m / z=17845$ ). Solutions of FimH $\mathrm{tr}_{\mathrm{tr}}$ and the photophores $\mathbf{2}, \mathbf{1 2}$, and $\mathbf{1 3}$ were applied in a ratio of 5:1. Samples were incubated at $37{ }^{\circ} \mathrm{C}$ to allow formation of the lectin-ligand complex and then irradiated at $\lambda \geq 320 \mathrm{~nm}$. This led to 1:1-photo-crosslinked products with the corresponding masses (Table 2).

In addition to the mass spectrometric analysis, dot-blots were performed with $\mathrm{FimH}_{\mathrm{tr}}$ and the photoactive mannosides. Affinity staining was carried out with a streptavidine-HRP conjugate and the chromogene 3,3'-diaminobenzidine (DAB). The biotin-labeled mannosides $\mathbf{1 2}$ and $\mathbf{1 3}$ gave violet spots on the nitrocellulose membrane when tested. Affino dot-blot with mannoside 2 , that does not contain a biotin moiety, was negative, as predicted. In addition, control experiments were carried out, leading to the expected results in all cases. Interestingly, photoaffinity probes $\mathbf{1 2}$ and $\mathbf{1 3}$ seem to exhibit unequal affinity to $\mathrm{FimH}_{\text {tr }}$ as suggested by the different intensity of color of the respective precipitates (Figure 3). Affinity staining using western blots led to analogous results (not shown).

\section{Conclusion}

In conclusion, we have demonstrated the synthesis of new biotin-labeled photoactive mannosides for photoaffinitylabeling of the bacterial lectin FimH. The target molecules 12 and 13 were selected after docking studies based on the structure of FimH and according to binding studies employing type 1-fimbriated E. coli. Photo-crosslinking was tested with the model peptide angiotensin II and the regiochemistry of the insertion reaction could be solved by MS/MS studies. Furthermore, photoaffinity-labeling of $\mathrm{FimH}_{\mathrm{tr}}$ was successful and could be demonstrated by mass spectrometric studies as well as dot-blot analysis.

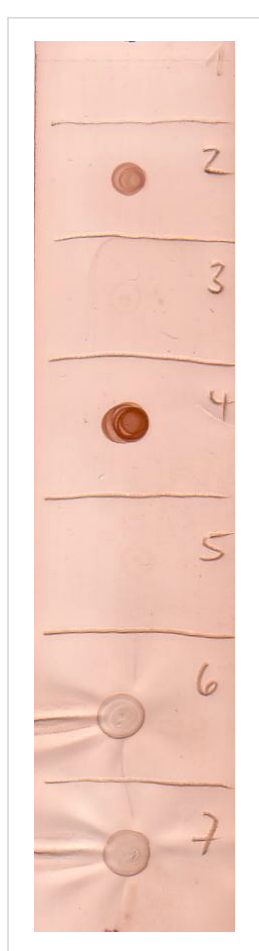

Lane 1: FimH $\mathrm{tr}_{\mathrm{tr}}$, irradiated

Lane 2: $\mathrm{FimH}_{\mathrm{tr}}$, 13, irradiated

Lane 3: FimH $_{\mathrm{tr}}$, 12, not irradiated

Lane 4: $\mathrm{FimH}_{\mathrm{tr}}$, 12, irradiated

Lane 5: $\mathrm{FimH}_{\mathrm{tr}}$, 13, not irradiated

Lane 6: 13, not irradiated

Lane 7: 12, not irradiated

Figure 3: Affino dot-blot with FimH $\mathrm{H}_{\mathrm{tr}}$ and photoactive mannosides applied to nitrocellulose disks. It was irradiated, incubated with streptavidine-HRP conjugate and stained by addition of the chromogene 3,3'diaminobenzidine. Photoaffinity probes 12 (lane 4) and 13 (lane 2) led to different color intensities, suggesting that ligand $\mathbf{1 2}$ is bound more tightly to $\mathrm{FimH}_{\mathrm{tr}}$ than ligand $\mathbf{1 3 .}$

The overall goal of this study is to identify mannose binding sites on the bacterial lectin FimH in solution. After photocrosslinking of the lectin with photoactive, biotin-labeled mannosidic ligands, proteolytic digestion of the products of photo-crosslinking, followed by affinity chromatography and mass-spectrometric analysis of the fragments, should allow the identification of the critical amino acid residues on FimH, according to the photoaffinity methodology. However, so far we

\begin{tabular}{|c|c|c|c|c|}
\hline $\begin{array}{c}\mathrm{FimH}_{\mathrm{tr}}^{\mathrm{a}} \\
\text { incubated with }\end{array}$ & $\begin{array}{c}\mathrm{FimH}_{\mathrm{tr}}^{\mathrm{b}} \\
\text { measured mass } \\
\mathrm{m} / \mathrm{z}\end{array}$ & $\begin{array}{l}\text { crosslinked product } \\
\text { measured mass } \\
\mathrm{m} / \mathrm{z}\end{array}$ & $\begin{array}{c}\Delta \text { mass } \\
m / z\left(\text { FimH }_{\mathrm{tr}}\right)-m / z \\
\text { (crosslinked product) }\end{array}$ & $\begin{array}{l}\Delta \text { mass } \\
\text { expected }\end{array}$ \\
\hline 2 & $17858[\mathrm{M}+\mathrm{H}]^{+}$ & $18200^{\mathrm{C}}[\mathrm{M}+\mathrm{H}]^{+}$ & 342 & $350^{e}$ \\
\hline 12 & $17905[\mathrm{M}+\mathrm{H}]^{+}$ & $18672^{\mathrm{d}}[\mathrm{M}+\mathrm{H}]^{+}$ & 767 & $804^{f}$ \\
\hline 13 & $17697[\mathrm{M}+\mathrm{H}]^{+}$ & $18500^{d}[M+H]^{+}$ & 803 & $804^{f}$ \\
\hline
\end{tabular}

aFor control experiments $\mathrm{FimH}_{\mathrm{tr}}$ was irradiated similarly without addition of photophore. Mass spectrometric analysis revealed that the protein FimH survived the conditions of irradiation without any damage.

${ }^{b}$ Calcd. mass $\mathrm{M}=17845 \mathrm{Da}$; measured values are acceptable within accuracy of the measurement.

cMeasured on 4700 Proteomics Analyzer (Applied Biosystems).

dMeasured on Bruker Biflex III.

${ }^{e}$ Based on the carbene resulting from irradiation of $2: \mathrm{C}_{15} \mathrm{H}_{17} \mathrm{~F}_{3} \mathrm{O}_{6}(\mathrm{M}=350 \mathrm{Da})$; measured $\Delta \mathrm{m}$-values acceptable within accuracy of the measurement.

${ }^{f} B a s e d$ on the carbene resulting from irradiation of 12 and 13, respectively: $\mathrm{C}_{34} \mathrm{H}_{47} \mathrm{~F}_{3} \mathrm{~N}_{6} \mathrm{O}_{11} \mathrm{~S}(\mathrm{M}=804 \mathrm{Da})$; measured $\Delta \mathrm{m}$-values acceptable within accuracy of the measurement. 
have not been successful in an unequivocal mass-spectrometric analysis of any proteolytic digest, we have obtained so far. Thus, this study is currently continued in our laboratory.

\section{Experimental \\ Docking studies}

Computer-aided modeling to predict binding of the various FimH ligands was carried out using FlexX flexible docking and consensus scoring as implemented in Sybyl 6.8 as described earlier [20]. Docking was based on published X-ray structures of the FimH CRD. This CRD was held fixed during the minimization, whereas the sugar ligand was allowed to change its conformation freely under the influence of the force field.

\section{ELISA}

ELISAs to determine $\mathrm{IC}_{50}$-values of the various FimH ligands were carried out with $E$. coli bacteria of strain HB101pPKL4 and mannan-coated microtiter plates as described earlier $[21,22]$.

\section{Mass spectrometry}

For mass spectrometric analyses of the photo-crosslinked products, a Bruker Biflex III instrument (MALDI-TOF-MS, Prof. Th. K. Lindhorst, CAU), or a Bruker Biflex II instrument (ESIFT-ICR-MS/MS, group of PD Dr. B. Lindner at the Research Center Borstel), or the 4700 Proteomics Analyzer mass spectrometer (Applied Biosystems MALDI-TOF/TOF-MS, group of Prof. M. Leippe, CAU) were used. Mass spectra were acquired using standard experimental sequences as provided by the manufacturer. Analysis of photo-crosslinking with angiotensin II is exemplified with diazirine $\mathbf{2}$ and presented in Figure 4.

\section{FimH truncate}

The amino acid sequence of the FimH truncate [24], $\mathrm{FimH}_{\mathrm{tr}}$, used in the photoaffinity labeling studies is as follows:

FACKTANGT AIPIGGGSAN VYVNLAPVVN VGQNLVVDLS TQIFCHNDYP ETITDYVTLQ RGSAYGGVLS NFSGTVKYSG SSYPFPTTSE TPRVVYNSRT DKPWPVALYL TPVSSAGGVA IKAGSLIAVL ILRQTNNYNS DDFQFVWNIY ANNDVVVPT GGHHHHHH

\section{Affino dot-blot}

Samples ( $2 \mu \mathrm{L}, 1.15$ mmolar) were applied on a nitrocellulose membrane, incubated with streptavidine-HRP conjugate and stained with 3,3'-diaminobenzidine.

\section{Methods and materials for synthesis}

Reactions were monitored by TLC on silica gel $\mathrm{GF}_{254}$ (Merck) with detection under UV light and by charring with $10 \%$ sulfuric acid in ethanol or using anisaldehyde and subsequent heating. Flash column chromatography was performed on silica gel $60(40-63 \mu \mathrm{m}$, Merck) and for RP-MPLC a Merck Licroprep RP-18 column (Büchi) was used. Preparative HPLC was accomplished on a Shimadzu LC-8a machine (LiChrosorb RP-8, HIBAR). NMR spectra were recorded on Bruker AMX 400, Bruker DRX 500 or Bruker Avance 600 instruments. Chemical shifts are relative to TMS or the solvent peaks of $\mathrm{CDCl}_{3}$ (7.24 ppm for ${ }^{1} \mathrm{H}, 77.0 \mathrm{ppm}$ for $\left.{ }^{13} \mathrm{C}\right)$ or $\mathrm{MeOD}$ (3.35 ppm and $4.78 \mathrm{ppm}$ for ${ }^{1} \mathrm{H}, 49.3 \mathrm{ppm}$ for ${ }^{13} \mathrm{C}$ ). Where necessary, assignments were based on 2D experiments (COSY, HSQC, HMBC or NOESY). IR spectra were taken with a Perkin Elmer FT IR Paragon 1000 (KBr). Optical rotations were measured with a Perkin-Elmer polarimeter $\left(22{ }^{\circ} \mathrm{C}, 589 \mathrm{~nm}\right.$, length of cuvette: $1 \mathrm{dm}$ ). For MS analysis of the synthetic products MALDI-TOF mass spectra were measured with a Bruker Biflex III with $19 \mathrm{kV}$ acceleration voltage. 4-Hydroxy- $\alpha$ cyanocinnamic acid (HCCA) was used as matrix, either as a saturated solution in a solvent mixture $(33 \% \mathrm{MeCN} /$ double distilled water and $0.1 \%$ TFA) or as saturated solution in acetone. Ionisation was effected with a nitrogen laser at $337 \mathrm{~nm}$. ESI-MS spectra of the synthesized derivatives were measured with an Applied Biosystems Mariner ESI-TOF 5280 and millipore $\mathrm{C}_{18}$-pipette tips were used for ZipTipping ${ }^{\circledR}$.

\section{$\mathrm{N}$-(Fluoren-9-ylmethoxycarbonyl)-4-[2-( $\alpha-D-m a n n o-$ pyranosyloxy)ethylamido]-L-aspartic acid tert-butyl ester (7)}

The aminoethyl mannoside 6 (200 mg, $0.90 \mathrm{mmol})$, HATU $(320 \mathrm{mg}, 0.90 \mathrm{mmol})$ and Fmoc-Asp-O $t \mathrm{Bu}(400 \mathrm{mg}$, $0.98 \mathrm{mmol}$ ) were dried under vacuum for $10 \mathrm{~min}$ and then dissolved in dry DMF $(12 \mathrm{~mL})$ under a nitrogen atmosphere. DIPEA ( $300 \mu \mathrm{L}, 2.25 \mathrm{mmol})$ was added and the reaction mixture stirred for $18 \mathrm{~h}$ at RT. The solvent was removed in vacuo and the residue purified by flash chromatography (ethyl acetate: $\mathrm{MeOH}: \mathrm{H}_{2} \mathrm{O}=6: 2: 1$ ). Pure product fractions were pooled, filtered, concentrated and the residual taken up in water. Lyophylisation gave the title compound $(531 \mathrm{mg}, 0.86 \mathrm{mmol}$, $95 \%$ ); $R_{\mathrm{f}}=0.86$ (ethyl acetate: $\mathrm{MeOH}: \mathrm{H}_{2} \mathrm{O}=6: 2: 1$ ).

${ }^{1} \mathrm{H}$ NMR (600 MHz, D $\left.4-\mathrm{MeOH}\right): \delta=7.84(\mathrm{~d}, 2 \mathrm{H}, J=7.6 \mathrm{~Hz}$, aryl-Fmoc), 7.71 (d, 2H $J=7.5 \mathrm{~Hz}$, aryl-Fmoc), 7.43 (t, 2H, $J=$ $7.5 \mathrm{~Hz}$, aryl-Fmoc), 7.35 (t, $2 \mathrm{H}, J=7.5 \mathrm{~Hz}$, aryl-Fmoc), 4.81 (d, $1 \mathrm{H}, J=1.5 \mathrm{~Hz}, \mathrm{H}-1 \mathrm{man}), 4.50(\mathrm{dd}, 1 \mathrm{H}, J=7.2 \mathrm{~Hz}, J=5.6 \mathrm{~Hz}$, $\mathrm{H} \alpha$-asp), 4.40 (dd, $1 \mathrm{H}, J=10.5 \mathrm{~Hz}, J=7.2 \mathrm{~Hz}$, Fmoc-CH $H$ ), $4.35(\mathrm{dd}, 1 \mathrm{H}, J=10.5 \mathrm{~Hz}, J=7.0 \mathrm{~Hz}$, Fmoc-CHH), $4.28(\mathrm{t}, 1 \mathrm{H}$, $J=7.0 \mathrm{~Hz}$, Fmoc-CH-CH$), 3.88(\mathrm{dd}, 1 \mathrm{H}, J=11.6 \mathrm{~Hz}, J=$ $\left.2.2 \mathrm{~Hz}, \operatorname{manOCH}_{2} \mathrm{CH} H\right), 3.87(\mathrm{dd}, 1 \mathrm{H}, J=3.5 \mathrm{~Hz}, J=1.8 \mathrm{~Hz}$, $\mathrm{H}-2 \mathrm{man}), 3.79(\mathrm{dd}, 1 \mathrm{H}, J=10.5 \mathrm{~Hz}, J=4.5 \mathrm{~Hz}$, manOCH $\left.\mathrm{HCH}_{2}\right), 3.75(\mathrm{dd}, 1 \mathrm{H}, J=11.7 \mathrm{~Hz}, J=5.9 \mathrm{~Hz}$, $\left.\operatorname{manOCH}{ }_{2} \mathrm{CHH}\right), 3.74(\mathrm{dd}, 1 \mathrm{H}, J=9.3 \mathrm{~Hz}, J=3.4 \mathrm{~Hz}$, 

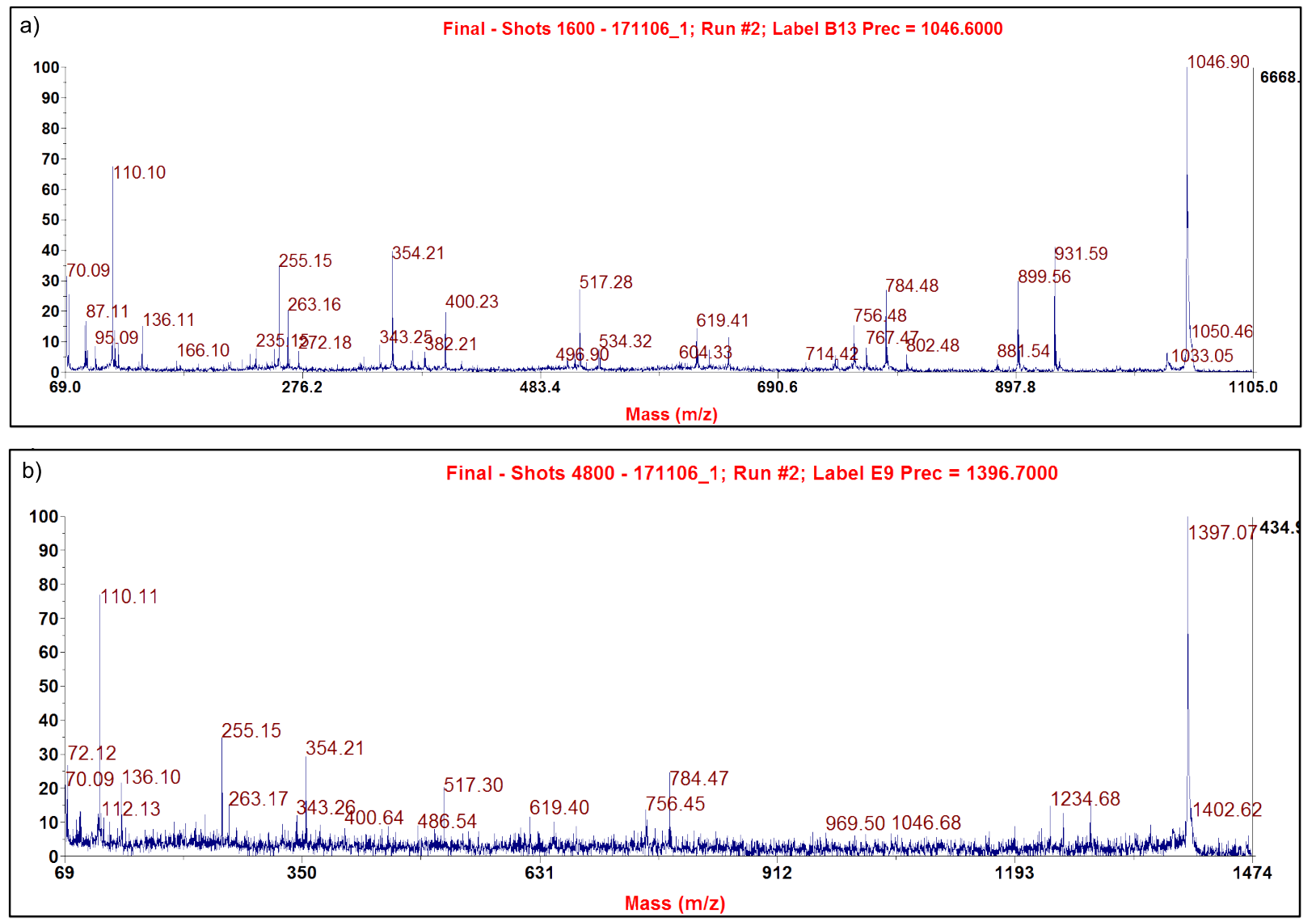

c)

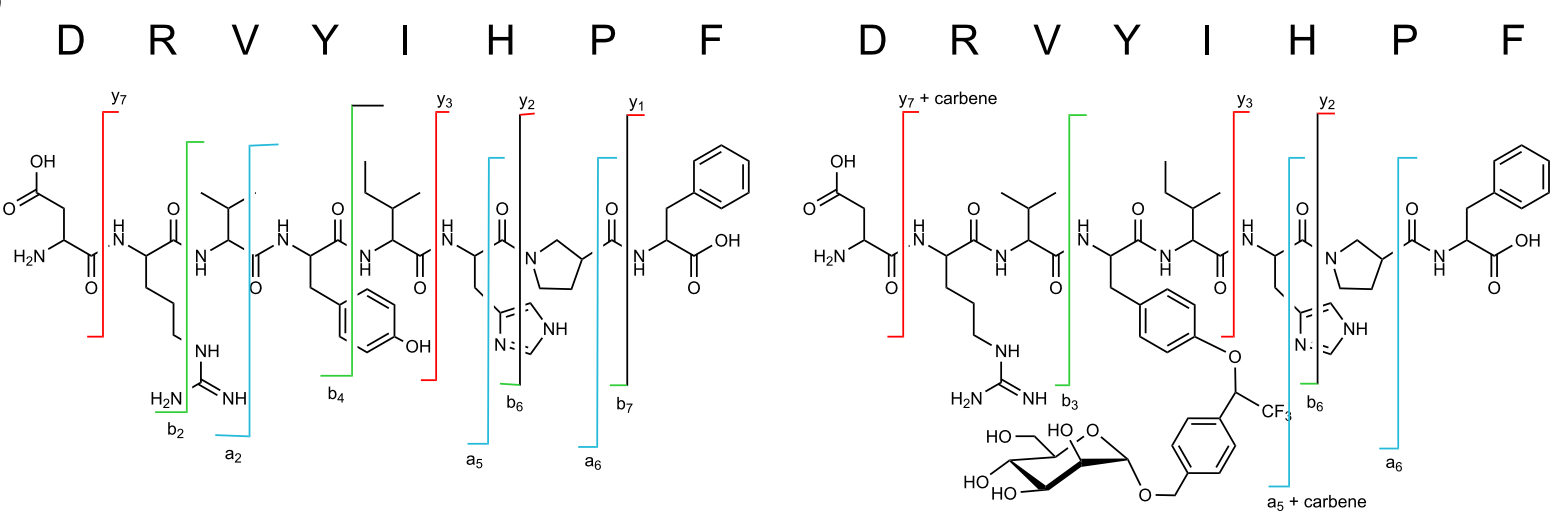

Figure 4: MS/MS spectra of angiotensin II (a) and of angiotensin II, photo-crosslinked with diazirine 2 (b), recorded on 4700 Proteomics Analyzer mass spectrometer (Applied Biosystems); (c) fragments of angiotensin II and photo-crosslinked angiotensin II according to Biemann's nomenclature (Table 3).

$\mathrm{H}-3 \operatorname{man}), 3.65$ (t, 1H, $J=9.5 \mathrm{~Hz}, \mathrm{H}-4 \mathrm{man}), 3.58$ (ddd, $1 \mathrm{H}, J=$ $9.7 \mathrm{~Hz}, J=5.7 \mathrm{~Hz}, J=2.1 \mathrm{~Hz}, \mathrm{H}-5 \mathrm{man}), 3.57$ (dd, $1 \mathrm{H}, J=$ $\left.10.2 \mathrm{~Hz}, J=4.3 \mathrm{~Hz}, \operatorname{manOC} H \mathrm{HCH}_{2}\right), 3.47(\mathrm{dd}, 1 \mathrm{H}, J=$ $14.2 \mathrm{~Hz}, J=6.2 \mathrm{~Hz}, \mathrm{H}-6 \mathrm{man}), 3.04$ (dd, $1 \mathrm{H}, J=14.2 \mathrm{~Hz}, J=$ $4.7 \mathrm{~Hz}, \mathrm{H}-6$ 'man), 2.78 (dd, $1 \mathrm{H}, J=15.1 \mathrm{~Hz}, J=5.4 \mathrm{~Hz}$, Hß-asp), 2.69 (dd, 1H, $J=15.2 \mathrm{~Hz}, J=7.3 \mathrm{~Hz}, \mathrm{H} \beta$ '-asp), 1.49 (s, 9H, OtBu) ppm; ${ }^{13} \mathrm{C}$ NMR (150.9 MHz, $\left.\mathrm{D}_{4}-\mathrm{MeOH}\right): \delta=$
$170.92($ Fmoc-C $=\mathrm{O}), 170.63(\mathrm{O} t \mathrm{Bu}-\mathrm{C}=\mathrm{O}), 156.92(\mathrm{C}-\gamma)$, $143.81,141.15,127.40,126.79,124.88,119.54$ (aryl-Fmoc),

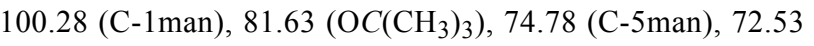
(C-3man), 72.05 (C-2man), 68.64 (C-4man), 68.12 (Fmoc$\left.\mathrm{CH}_{2}\right), 67.17\left(\mathrm{manOCH}_{2} \mathrm{CH}_{2}\right), 66.71\left(\mathrm{manOCH}_{2} \mathrm{CH}_{2}\right), 51.63$ (C- $\alpha), 48.30$ (CH-Fmoc), 40.35 (C-6), 38.55 (C- $\beta$ ), 28.21 $\left(\mathrm{OC}\left(\mathrm{CH}_{3}\right)_{3}\right)$ ppm. 
Table 3: Assignment of peptide fragment ion pattern according to Biemann [25]; left two columns: angiotensin; right two columns photo-crosslinked product of angiotensin and diazirine 2 (Figure 4).

\begin{tabular}{|c|c|c|c|}
\hline $\begin{array}{c}\text { MS-MS experiment with } \\
\text { angiotensin II } \\
m / z\end{array}$ & $\begin{array}{l}\text { corresponding } \\
\text { fragment }\end{array}$ & $\begin{array}{l}\text { photo-crosslinking of } \\
\text { angiotensin II and 2; } \\
\text { MS-MS experiment } \\
\mathrm{m} / \mathrm{z}\end{array}$ & $\begin{array}{l}\text { corresponding } \\
\text { fragment }\end{array}$ \\
\hline 1046.90 & {$[\mathrm{MH}]^{+}$} & 1397.07 & {$[\mathrm{MH}]^{+}$} \\
\hline 931.59 & $\mathrm{y}_{7}$ & 1281.47 & {$[\mathrm{MH}-\mathrm{D}]^{+}$} \\
\hline 899.56 & $\mathrm{~b}_{7}-\mathrm{H}_{2} \mathrm{O}$ & 1046.68 & 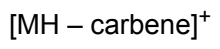 \\
\hline 881.54 & $b_{7}$ & 969.50 & {$\left[a_{5}+\right.$ carbene $]$} \\
\hline 802.48 & $\mathrm{~b}_{6}-\mathrm{H}_{2} \mathrm{O}$ & & \\
\hline 784.48 & $b_{6}$ & 784.47 & $b_{6}$ \\
\hline 767.47 & $\mathrm{~b}_{6}-\mathrm{NH}_{3}$ & 756.45 & $a_{6}$ \\
\hline 756.48 & $a_{6}$ & 619.40 & $a_{5}$ \\
\hline 619.41 & $a_{5}$ & 517.30 & $\mathrm{~b}_{4}-\mathrm{NH}_{3}$ \\
\hline 534.32 & $\mathrm{~b}_{4}$ & 486.54 & {$[\mathrm{Y}+$ carbene $]$} \\
\hline 517.28 & $\mathrm{~b}_{4}-\mathrm{NH}_{3}$ & 400.64 & $\mathrm{y}_{3}$ \\
\hline 400.23 & $\mathrm{y}_{3}$ & & \\
\hline 354.21 & $b_{3}-N_{3}$ & 354.21 & $b_{3}-N_{3}$ \\
\hline 343.25 & $a_{3}$ & 343.26 & $a_{3}$ \\
\hline 272.18 & $b_{2}$ & & \\
\hline 263.16 & $\mathrm{y}_{2}$ & 263.17 & $\mathrm{y}_{2}$ \\
\hline 255.15 & $\mathrm{~b}_{2}-\mathrm{NH}_{3}$ & 255.15 & $\mathrm{~b}_{2}-\mathrm{NH}_{3}$ \\
\hline 235.12 & $\mathrm{HP}$ & & \\
\hline 166.10 & $\mathrm{y}_{1}$ & & \\
\hline 136.11 & $Y$ & 136.10 & $Y$ \\
\hline 110.10 & $\mathrm{H}$ & 110.11 & $\mathrm{H}$ \\
\hline 87.11 & $\mathrm{R}$ & 72.12 & $\mathrm{~V}$ \\
\hline 70.09 & $P$ & 70.01 & $P$ \\
\hline
\end{tabular}

MALDI-TOF-MS: $m / z=639.2[\mathrm{M}+\mathrm{Na}]^{+}, 656.2[\mathrm{M}+\mathrm{K}]^{+}$; ESI-MS: $m / z=639.26[\mathrm{M}+\mathrm{Na}]^{+}(616.66$ calcd. for $\mathrm{C}_{31} \mathrm{H}_{40} \mathrm{~N}_{2} \mathrm{O}_{11}$ ).

\section{$N$-(Fluoren-9-ylmethoxycarbonyl)-4-(tert-butyl ester)-L-aspartic acid [2-( $\alpha-D-m a n n o p y r a n o s y l o x y)$ ethyl]-amide (8)}

The aminoethyl mannoside 6 (200 $\mathrm{mg}, 0.90 \mathrm{mmol})$, HATU $(320 \mathrm{mg}, 0.90 \mathrm{mmol}$ ) and Fmoc- Fmoc-Asp $(\mathrm{O} t \mathrm{Bu})-\mathrm{OH}$ (400 mg, $0.98 \mathrm{mmol}$ ) were dried under vacuum for $10 \mathrm{~min}$ and then dissolved in dry DMF (12 mL) under a nitrogen atmosphere. DIPEA ( $300 \mu \mathrm{L}, 2.25 \mathrm{mmol})$ was added and the reaction mixture stirred for $18 \mathrm{~h}$ at RT. The solvent was removed in vacuo and the residue purified by flash chromatography (ethyl acetate: $\mathrm{MeOH}: \mathrm{H}_{2} \mathrm{O}=6: 2: 1$ ). Pure product fractions were pooled, filtered, concentrated and the residue taken up in water. Lyophylisation gave the title compound (536 $\mathrm{mg}, 0.87 \mathrm{mmol}, 96 \%$ ); $R_{\mathrm{f}}=0.75$ (ethyl acetate: $\mathrm{MeOH}: \mathrm{H}_{2} \mathrm{O}=$ $6: 2: 1)$.

${ }^{1} \mathrm{H}$ NMR (500 MHz, D $\left.4-\mathrm{MeOH}\right): \delta=7.82(\mathrm{dd}, 2 \mathrm{H}, J=7.6 \mathrm{~Hz}$, $J=3.5 \mathrm{~Hz}$, aryl-Fmoc), 7.71 (t, $2 \mathrm{H}, J=7.7 \mathrm{~Hz}$, aryl-Fmoc), $7.42(\mathrm{dd}, 2 \mathrm{H}, J=7.5 \mathrm{~Hz}, J=3.4 \mathrm{~Hz}$, aryl-Fmoc), $7.34(\mathrm{dd}, 2 \mathrm{H}$, $J=6.9 \mathrm{~Hz}, J=1.1 \mathrm{~Hz}$, aryl-Fmoc), $4.81(\mathrm{~d}, 1 \mathrm{H}, J=1.4 \mathrm{~Hz}$, H-1man), 4.52 (dd, 1H, $J=8.7 \mathrm{~Hz}, J=5.2 \mathrm{~Hz}, \mathrm{H} \alpha$-asp), 4.48 $(\mathrm{dd}, 1 \mathrm{H}, J=10.5 \mathrm{~Hz}, J=7.0 \mathrm{~Hz}$, Fmoc-CHH), 4.39 (dd, 1H, $J=$ $10.7 \mathrm{~Hz}, J=6.6 \mathrm{~Hz}$, Fmoc-CHH), $4.27(\mathrm{t}, 1 \mathrm{H}, J=7.0 \mathrm{~Hz}$, Fmoc-CH), $3.88(\mathrm{dd}, 1 \mathrm{H}, J=12.1 \mathrm{~Hz}, J=2.2 \mathrm{~Hz}$, $\left.\operatorname{manOCH}_{2} \mathrm{CH} H\right), 3.86(\mathrm{dd}, 1 \mathrm{H}, J=1.4 \mathrm{~Hz}, J=3.0 \mathrm{~Hz}$, H-2man), $3.79(\mathrm{dd}, 1 \mathrm{H}, J=10.7 \mathrm{~Hz}, J=6.4 \mathrm{~Hz}$, manOCH $\left.\mathrm{HCH}_{2}\right), 3.73(\mathrm{dd}, 1 \mathrm{H}, J=8.8 \mathrm{~Hz}, J=3.0 \mathrm{~Hz}$, H-3man), $3.75(\mathrm{dd}, 1 \mathrm{H}, J=11.8 \mathrm{~Hz}, J=5.8 \mathrm{~Hz}$, manOCH$\left.{ }_{2} \mathrm{CHH}\right) 3.65$ (t, $1 \mathrm{H}, J=9.6 \mathrm{~Hz}, \mathrm{H}-4 \mathrm{man}$ ), 3.57 (ddd, $1 \mathrm{H}, J=10.3 \mathrm{~Hz}, J=7.1 \mathrm{~Hz}, J=4.7 \mathrm{~Hz}, \mathrm{H}-5 \mathrm{man}), 3.56$ (dd, $1 \mathrm{H}$, $\left.J=10.8 \mathrm{~Hz}, J=5.8 \mathrm{~Hz}, \operatorname{manOCH} \mathrm{HCH}_{2}\right), 3.48(\mathrm{dd}, 1 \mathrm{H}, J=$ $13.9 \mathrm{~Hz}, J=7.6 \mathrm{~Hz}, \mathrm{H}-6 \mathrm{man}), 3.42(\mathrm{dd}, 1 \mathrm{H}, J=13.9 \mathrm{~Hz}, J=$ $5.0 \mathrm{~Hz}, \mathrm{H}-6$ 'man), $2.82(\mathrm{dd}, 1 \mathrm{H}, J=16.1 \mathrm{~Hz}, J=5.1 \mathrm{~Hz}$, $\mathrm{H} \beta$-asp), 2.60 (dd, $1 \mathrm{H}, J=16.1 \mathrm{~Hz}, J=8.9 \mathrm{~Hz}, \mathrm{H} \beta$ '-asp), 1.47 (s, 9H, OC( $\left.\left(\mathrm{CH}_{3}\right)_{3}\right) \mathrm{ppm} ;{ }^{13} \mathrm{C} \mathrm{NMR}\left(150.92 \mathrm{MHz}, \mathrm{D}_{4}-\mathrm{MeOH}\right): \delta$ $=173.48(\mathrm{O} t \mathrm{Bu}-\mathrm{C}=\mathrm{O}), 172.48($ Fmoc $-\mathrm{C}=\mathrm{O}), 171.39(\mathrm{NH}-$ $\left.(\mathrm{C}=\mathrm{O})_{\mathrm{asp}}\right), 145.22,142.59,128.79,128.17,126.23,120.91$

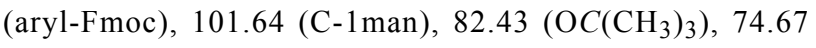
(C-5man), 72.52 (C-3man), 72.05 (C-2man), 68.67 (C-4man), $68.19\left(\mathrm{Fmoc}-\mathrm{CH}_{2}\right), 67.06\left(\mathrm{manOCH} \mathrm{CH}_{2}\right), 62.84$ 
$\left(\mathrm{manOCH}_{2} \mathrm{CH}_{2}\right), 53.32$ (C- $\left.\alpha\right), 48.34$ (CH-Fmoc), 40.42 (C-6man), $38.74(\mathrm{C}-\beta), 28.33\left(\mathrm{C}\left(\mathrm{CH}_{3}\right)_{3}\right) \mathrm{ppm}$.

MALDI-TOF-MS: $m / z=639.2[\mathrm{M}+\mathrm{Na}]^{+}$; ESI-MS: $m / z=$ $639.26[\mathrm{M}+\mathrm{Na}]^{+}\left(616.66\right.$ calcd. for $\left.\mathrm{C}_{31} \mathrm{H}_{40} \mathrm{~N}_{2} \mathrm{O}_{11}\right)$.

N-(Fluoren-9-ylmethoxycarbonyl)-4-[2-(a-D-mannopyranosyloxy)ethyl]-1-[(+)-biotinylamidopropyl]-Laspartic acid diamide (9)

The glycoamino acid 7 (220 mg, $0.36 \mathrm{mmol})$ was dissolved in $80 \%$ aq TFA $(5 \mathrm{~mL})$ and stirred at RT for $60 \mathrm{~min}$ to cleave the tert-butyl ester. When the deprotection reaction was complete (TLC control in ethyl acetate: $\mathrm{MeOH}: \mathrm{H}_{2} \mathrm{O}=6: 2: 1$ ) the solvent was removed in vacuo and the residue suspended in $\mathrm{MeOH}$, filtered and the filtrate concentrated under reduced pressure. The resulting crude product was combined with HATU (150 mg, $0.43 \mathrm{mmol}$ ), (+)-biotinylamidopropylammonium trifluoroacetate $(170 \mathrm{mg}, 0.41 \mathrm{mmol})$ and dried for $30 \mathrm{~min}$ under vacuum. DMF $(5 \mathrm{~mL})$ and DIPEA $(350 \mu \mathrm{L}, 2.63 \mathrm{mmol})$ were then added under a nitrogen atmosphere. The reaction mixture was stirred overnight at RT, the solvent removed in vacuo and the residue purified by HPLC $\left(\mathrm{MeCN}-\mathrm{H}_{2} \mathrm{O}\right.$ gradient: $0-5 \mathrm{~min}$ $100 \% \mathrm{H}_{2} \mathrm{O}, 5-20 \min 60 \% \mathrm{H}_{2} \mathrm{O}, 20-30 \min 40 \% \mathrm{H}_{2} \mathrm{O}$, $30-40 \min 0 \% \mathrm{H}_{2} \mathrm{O}, 40-50 \mathrm{~min} 0 \% \mathrm{H}_{2} \mathrm{O}, 50-60 \mathrm{~min}$ $\left.100 \% \mathrm{H}_{2} \mathrm{O}\right)$. The title compound was obtained after lyophylisation (145 mg, $0.17 \mathrm{mmol}, 48 \%$ ); $R_{\mathrm{f}}=0.47$ (ethyl acetate: $\left.\mathrm{MeOH}: \mathrm{H}_{2} \mathrm{O}=6: 2: 1\right)$.

${ }^{1} \mathrm{H}$ NMR (500 MHz, $\left.\mathrm{CD}_{3} \mathrm{CN}: \mathrm{D}_{2} \mathrm{O}=1: 1\right): \delta=7.85$ (d, 2H, $J=$ $7.6 \mathrm{~Hz}$, aryl-Fmoc), $7.71(\mathrm{dd}, 2 \mathrm{H}, J=6.8 \mathrm{~Hz}, J=4.2 \mathrm{~Hz}$, arylFmoc), 7.45 (t, 2H, $J=7.4 \mathrm{~Hz}$, Fmoc-H), 7.37 (t, 2H, $J=$ $7.5 \mathrm{~Hz}, J=4.1 \mathrm{~Hz}$, Fmoc-H), 4.80 (d, 1H, $J=1.6 \mathrm{~Hz}, \mathrm{H}-1 \mathrm{man})$, $4.51\left(\mathrm{dd}, 1 \mathrm{H}, J=7.6 \mathrm{~Hz}, J=5.8 \mathrm{~Hz}\right.$, biotin- $\left.\mathrm{NHCHCH}_{2} \mathrm{~S}\right), 4.42$ (dd, $1 \mathrm{H}, J=11.8 \mathrm{~Hz}, J=6.8 \mathrm{~Hz}$, manOCH $\mathrm{HCH}_{2}$ ), 4.38 (dd, $1 \mathrm{H}, J=11.8 \mathrm{~Hz}, J=7.3 \mathrm{~Hz}$, manOCH$\left.H \mathrm{CH}_{2}\right), 4.27$ (d, $1 \mathrm{H}, J=$ $7.2 \mathrm{~Hz}$, biotin-NHCHCHalkyl), $4.24(\mathrm{t}, 1 \mathrm{H}, J=6.8 \mathrm{~Hz}$, H $\alpha$-asp), 3.86 (dd, 1H, $J=3.4 \mathrm{~Hz}, J=1.7 \mathrm{~Hz}, \mathrm{H}-2 \mathrm{man}$ ), 3.77 (dd, $1 \mathrm{H}, J=12.1 \mathrm{~Hz}, J=2.2 \mathrm{~Hz}, \mathrm{H}-6 \mathrm{man}), 3.69$ (dd, 1H, $J=$ $9.6 \mathrm{~Hz}, J=3.9 \mathrm{~Hz}$. H-3man), 3.68 (dd, $1 \mathrm{H}, J=12.2 \mathrm{~Hz}, J=$ $3.6 \mathrm{~Hz}, \mathrm{H}-6$ 'man), 3.65 (dd, 1H, $J=11.9 \mathrm{~Hz}, J=6.9 \mathrm{~Hz}$, Fmoc$\mathrm{CH} H), 3.59$ (t, 1H, $J=9.6 \mathrm{~Hz}, \mathrm{H}-4 \mathrm{man}), 3.53$ (ddd, $1 \mathrm{H}, J=$ $9.9 \mathrm{~Hz}, J=5.5 \mathrm{~Hz}, J=2.2 \mathrm{~Hz}, \mathrm{H}-5 \mathrm{man}), 3.50(\mathrm{dd}, 1 \mathrm{H}, J=$ $11.2 \mathrm{~Hz}, J=6.7 \mathrm{~Hz}$, Fmoc-CH $H$ ), 3.41 (dd, 1H, $J=14.1 \mathrm{~Hz}, J$ $\left.=5.3 \mathrm{~Hz}, \operatorname{manOCH}{ }_{2} \mathrm{CH} H\right), 3.28(\mathrm{ddd}, 1 \mathrm{H}, J=14.2 \mathrm{~Hz}, J=$ $\left.5.7 \mathrm{~Hz}, \operatorname{manOCH}_{2} \mathrm{CHH}\right), 3.16(\mathrm{dd}, 1 \mathrm{H}, J=9.3 \mathrm{~Hz}, J=6.9 \mathrm{~Hz}$, $\mathrm{NH}(\mathrm{C}=\mathrm{O}) \mathrm{CH} \mathrm{H}-\mathrm{CH}_{2}-\mathrm{CH}_{2}-\mathrm{CH}_{2}$-biotin), 3.15 (t, $1 \mathrm{H}, J=7.4 \mathrm{~Hz}$, biotin-NHCHCHalkyl), $3.12(\mathrm{dd}, 1 \mathrm{H}, J=9.5 \mathrm{~Hz}, J=6.6 \mathrm{~Hz}$, $\mathrm{NH}(\mathrm{C}=\mathrm{O}) \mathrm{CH} H-\mathrm{CH}_{2}-\mathrm{CH}_{2}-\mathrm{CH}_{2}$-biotin $), 2.87$ (dd, $1 \mathrm{H}, J=12.8$ $\mathrm{Hz}, J=5.1 \mathrm{~Hz}$, biotin-NHCHCHHS), 2.69 (dd, $1 \mathrm{H}, J=12.9$ $\mathrm{Hz}, J=4.9 \mathrm{~Hz}$, biotin-NHCHCHHS), 2.67 (dd, $1 \mathrm{H}, J=13.7$ $\left.\mathrm{Hz}, J=7.5 \mathrm{~Hz}, \mathrm{HN}-\mathrm{CH}-\mathrm{CH}_{2}-\mathrm{CH}_{2}-\mathrm{NH}\right), 2.59$ (dd, $1 \mathrm{H}, J=$ $\left.13.9 \mathrm{~Hz}, J=7.8 \mathrm{~Hz}, \mathrm{HN}-\mathrm{CH} H-\mathrm{CH}_{2}-\mathrm{CH}_{2}-\mathrm{NH}\right), 2.56$ (dd, $1 \mathrm{H}, J$ $\left.=14.2 \mathrm{~Hz}, J=7.2 \mathrm{~Hz}, \mathrm{HN}-\mathrm{CH}_{2}-\mathrm{CH}_{2}-\mathrm{CHH}-\mathrm{NH}\right), 2.53$ (dd, $1 \mathrm{H}$, $J=14.0 \mathrm{~Hz}, J=6.8 \mathrm{~Hz}, \mathrm{HN}-\mathrm{CH}_{2}-\mathrm{CH}_{2}-\mathrm{CH} H-\mathrm{NH}$ ), 2.15 (t, $1 \mathrm{H}$, $J=7.3 \mathrm{~Hz}, \mathrm{CH}-\mathrm{Fmoc}$ ), 2.13 (d, 1H, $J=6.8 \mathrm{~Hz}, \mathrm{H} \beta$-asp), 2.11 (d, $1 \mathrm{H}, J=6.5 \mathrm{~Hz}, \mathrm{H} \beta$ '-asp), $1.66(\mathrm{dd}, 1 \mathrm{H}, J=14.3 \mathrm{~Hz}, J=$ $7.6 \mathrm{~Hz}, \mathrm{NH}(\mathrm{C}=\mathrm{O}) \mathrm{CH}_{2}-\mathrm{CH}_{2}-\mathrm{CH}_{2}-\mathrm{CHH}$-biotin), 1.64 (dd, $1 \mathrm{H}, J$ $\left.=13.9 \mathrm{~Hz}, J=7.0 \mathrm{~Hz}, \mathrm{HN}-\mathrm{CH}_{2}-\mathrm{CH} \mathrm{H}-\mathrm{CH}_{2}-\mathrm{NH}\right), 1.62(\mathrm{dd}, 1 \mathrm{H}$, $J=14.0 \mathrm{~Hz}, J=7.2 \mathrm{~Hz}, \mathrm{HN}-\mathrm{CH}_{2}-\mathrm{CH} H-\mathrm{CH}_{2}-\mathrm{NH}$ ), 1.59 (dd, $1 \mathrm{H}, J=14.5 \mathrm{~Hz}, J=7.0 \mathrm{~Hz}, \mathrm{NH}(\mathrm{C}=\mathrm{O}) \mathrm{CH}_{2}-\mathrm{CH}_{2}-\mathrm{CH}_{2}-\mathrm{CH} H-$ biotin), 1.54 (dd, $1 \mathrm{H}, J=15.3 \mathrm{~Hz}, J=8.0 \mathrm{~Hz}, \mathrm{NH}(\mathrm{C}=\mathrm{O}) \mathrm{CH}_{2-}$ $\mathrm{CH}_{2}-\mathrm{CH} \mathrm{H}-\mathrm{CH}_{2}$-biotin), 1.49 (dd, $1 \mathrm{H}, J=15.3 \mathrm{~Hz}, J=8.1 \mathrm{~Hz}$, $\mathrm{NH}(\mathrm{C}=\mathrm{O}) \mathrm{CH}_{2}-\mathrm{CH}_{2}-\mathrm{CH} H-\mathrm{CH}_{2}$-biotin $), 1.33(\mathrm{dd}, 1 \mathrm{H}, J=$ $15.2 \mathrm{~Hz}, J=7.5 \mathrm{~Hz}, \mathrm{NH}(\mathrm{C}=\mathrm{O}) \mathrm{CH}_{2}-\mathrm{CH} \mathrm{H}-\mathrm{CH}_{2}-\mathrm{CH}_{2}$-biotin), $1.28\left(\mathrm{dd}, 1 \mathrm{H}, J=15.0 \mathrm{~Hz}, J=7.3 \mathrm{~Hz}, \mathrm{NH}(\mathrm{C}=\mathrm{O}) \mathrm{CH}_{2}-\mathrm{CH} H-\right.$ $\mathrm{CH}_{2}-\mathrm{CH}_{2}$-biotin) ppm; ${ }^{13} \mathrm{C}$ NMR (125.75 MHz; $\mathrm{CD}_{3} \mathrm{CN}: \mathrm{D}_{2} \mathrm{O}=$ 1:1): $\delta=180.86(\mathrm{C}-\gamma), 176.52\left(\mathrm{C}_{\text {asp }}(\mathrm{O})-\mathrm{NH}\right.$-propyl $), 173.26$ $\left(\mathrm{C}_{\text {biotin }}(\mathrm{O})-\mathrm{NH}\right.$-propyl), $172.17\left((\mathrm{NH})_{2} \mathrm{C}=\mathrm{O}\right), 165.62$ (Fmoc$\mathrm{C}=\mathrm{O}$ ), 144.81, 142.0, 128.93, 128.36, 126.25 (aryl-Fmoc), 100.73 (C-1 man), 73.82 (C-5man), 71.68 (C-2man), 71.12 (C-3man), 67.86 (Fmoc- $\left.\mathrm{CH}_{2}\right), 67.69$ (C-4man), 66.75 ( $m a n O C \mathrm{H}_{2} \mathrm{CH}_{2}$ ), 63.0 (biotin-NHCHCHalkyl), 62.0 (C-6man), 61.07 (biotin- $\mathrm{NHCHCH}_{2} \mathrm{~S}$ ), 56.30 (biotin-NHCHCHalkyl), 53.14 (C- $\alpha) 47.81$ (CH-Fmoc), 40.79 (biotin- $\mathrm{CH}_{2}$ ), 39.89 $\left(\mathrm{manOCH}_{2} \mathrm{CH}_{2}\right), 38.45,37.64\left(\mathrm{HN}-\mathrm{CH}_{2}-\mathrm{CH}_{2}-\mathrm{CH}_{2}-\mathrm{NH}\right), 37.59$ (C(O)- $\mathrm{CH}_{2}-\mathrm{CH}_{2}-\mathrm{CH}_{2}-\mathrm{CH}_{2}$-biotin), 36.52 (C- $\beta$ ), 29.29 (HN$\mathrm{CH}_{2}-\mathrm{CH}_{2}-\mathrm{CH}_{2}-\mathrm{NH}$ ), 29.09 (C(O)- $\mathrm{CH}_{2}-\mathrm{CH}_{2}-\mathrm{CH}_{2}-\mathrm{CH}_{2}$-biotin), 28.80 (C(O)- $\mathrm{CH}_{2}-\mathrm{CH}_{2}-\mathrm{CH}_{2}-\mathrm{CH}_{2}$-biotin), 26.27 (C(O)- $\mathrm{CH}_{2}-$ $\mathrm{CH}_{2}-\mathrm{CH}_{2}-\mathrm{CH}_{2}$-biotin) ppm.

MALDI-TOF-MS: $m / z=843.5[\mathrm{M}+\mathrm{H}]^{+}, 865.4[\mathrm{M}+\mathrm{Na}]^{+}$, $881.4[\mathrm{M}+\mathrm{K}]^{+},\left(842.96\right.$ calcd. for $\left.\mathrm{C}_{40} \mathrm{H}_{54} \mathrm{~N}_{6} \mathrm{O}_{12} \mathrm{~S}\right)$; ESI-MS: $m / z=865.44[\mathrm{M}+\mathrm{Na}]^{+}(842.96$ calcd. for $\mathrm{C}_{40} \mathrm{H}_{54} \mathrm{~N}_{6} \mathrm{O}_{12} \mathrm{~S}$ ).

\section{N-(Fluoren-9-ylmethoxycarbonyl)-4-[(+)-biotinylami-} dopropyl]-1-[2-(a-D-mannopyranosyloxy)ethyl]-Laspartic acid diamide (10)

The glycoamino acid 8 (250 $\mathrm{mg}, 0.41 \mathrm{mmol})$ was dissolved in $80 \%$ aq TFA $(6 \mathrm{~mL})$ and stirred at RT for 60 min to cleave the tert-butyl ester. When the deprotection reaction was complete (TLC control in ethyl acetate: $\mathrm{MeOH}: \mathrm{H}_{2} \mathrm{O}=6: 2: 1$ ) the solvent was removed in vacuo and the residue suspended in $\mathrm{MeOH}$, filtered and the filtrate concentrated under reduced pressure. The resulting crude product was combined with HATU (98.1 mg, $0.28 \mathrm{mmol}$ ) and (+)-biotinylamidopropylammonium trifluoroacetate $(109 \mathrm{mg}, 0.26 \mathrm{mmol})$, and dried for $30 \mathrm{~min}$ under vacuum. DMF (4 mL) and DIPEA (220 $\mu \mathrm{L}, 1.65 \mathrm{mmol})$ were then added under a nitrogen atmosphere. The reaction mixture was stirred overnight at RT, the solvent removed in vacuo and the residue purified by HPLC $\left(\mathrm{MeCN}-\mathrm{H}_{2} \mathrm{O}\right.$ gradient: 0-5 $\min 100 \% \mathrm{H}_{2} \mathrm{O}, 5-20 \min 60 \% \mathrm{H}_{2} \mathrm{O}, 20-30 \min 40 \% \mathrm{H}_{2} \mathrm{O}$, 
$30-40 \min 0 \% \mathrm{H}_{2} \mathrm{O}, 40-50 \min 0 \% \mathrm{H}_{2} \mathrm{O}, 50-60 \mathrm{~min}$ $100 \% \mathrm{H}_{2} \mathrm{O}$ ). The title compound was obtained after lyophylisation $(90.4 \mathrm{mg}, 0.11 \mathrm{mmol}, 26 \%) ; R_{\mathrm{f}}=0.54$ (ethyl acetate: $\left.\mathrm{MeOH}: \mathrm{H}_{2} \mathrm{O}=6: 2: 1\right)$.

${ }^{1} \mathrm{H}$ NMR $\left(600 \mathrm{MHz}, \mathrm{CD}_{3} \mathrm{CN}: \mathrm{D}_{2} \mathrm{O}, 1: 1\right): \delta=7.85(\mathrm{~d}, 2 \mathrm{H}, J=$ $7.6 \mathrm{~Hz}$, Fmoc-H), 7.67 (d, 2H, $J=7.5 \mathrm{~Hz}$, Fmoc-H), 7.45 (t, $2 \mathrm{H}, J=7.4 \mathrm{~Hz}$, Fmoc-H), $7.38(\mathrm{td}, 2 \mathrm{H}, J=7.5 \mathrm{~Hz}, J=0.9 \mathrm{~Hz}$, Fmoc-H), 4.77 (d, 1H, $J=1.7 \mathrm{~Hz}, \mathrm{H}-1 \mathrm{man}), 4.45$ (dd, 1H, $J=$ $6.7 \mathrm{~Hz}, J=4.5 \mathrm{~Hz}$, biotin-NHCHCH $\left.\mathrm{N}_{2} \mathrm{~S}\right), 4.43$ (t, $1 \mathrm{H}, J=6.8 \mathrm{~Hz}$, $\mathrm{H \alpha}$-asp), 4.40 (dd, $1 \mathrm{H}, J=12.2 \mathrm{~Hz}, J=5.5 \mathrm{~Hz}$, Fmoc-CHH), 4.37 (dd, $1 \mathrm{H}, J=12.0 \mathrm{~Hz}, J=5.3 \mathrm{~Hz}$, Fmoc-CHH), 4.29 (dd, $1 \mathrm{H}, J=5.5 \mathrm{~Hz}, J=4.4 \mathrm{~Hz}, \mathrm{CH}-\mathrm{Fmoc}), 4.27$ (dd, $1 \mathrm{H}, J=$ $6.5 \mathrm{~Hz}, J=4.7 \mathrm{~Hz}$, biotin-NHCHCHalkyl), 3.83 (dd, $1 \mathrm{H}, J=$ $3.2 \mathrm{~Hz}, J=1.6 \mathrm{~Hz}, \mathrm{H}-2 \mathrm{man}), 3.77$ (dd, $1 \mathrm{H}, J=12.2 \mathrm{~Hz}, \mathrm{~J}=$ $\left.6.5 \mathrm{~Hz}, \operatorname{manOCH} \mathrm{HCH}_{2}\right), 3.69(\mathrm{dd}, 1 \mathrm{H}, J=9.7 \mathrm{~Hz}, J=3.2 \mathrm{~Hz}$, H-3man), $3.66(\mathrm{dd}, 1 \mathrm{H}, J=12.1 \mathrm{~Hz}, J=6.9 \mathrm{~Hz}$, $\left.\operatorname{manOCH} \mathrm{HCH}_{2}\right), 3.64(\mathrm{dd}, 1 \mathrm{H}, J=12.0 \mathrm{~Hz}, J=5.3 \mathrm{~Hz}$, H-6man), 3.58 (t, 1H, $J=9.8 \mathrm{~Hz}, \mathrm{H}-4 \mathrm{man}$ ), 3.51 (ddd dd, 1H, $J$ $=9.8 \mathrm{~Hz}, J=5.5 \mathrm{~Hz}, \mathrm{H}-5 \mathrm{man}), 3.50(\mathrm{dd}, 1 \mathrm{H}, J=11.9 \mathrm{~Hz}, J=$ $5.6 \mathrm{~Hz}, \mathrm{H}-6$ 'man), $3.43(\mathrm{dd}, 1 \mathrm{H}, J=14.4 \mathrm{~Hz}, J=6.5 \mathrm{~Hz}$, $\left.\operatorname{manOCH}_{2} \mathrm{CH} H\right), 3.33(\mathrm{dd}, 1 \mathrm{H}, J=13.9 \mathrm{~Hz}, J=6.1 \mathrm{~Hz}$, $\left.\operatorname{manOCH}_{2} \mathrm{CHH}\right), 3.17(\mathrm{td}, 1 \mathrm{H}, J=7.1 \mathrm{~Hz}, J=6.9 \mathrm{~Hz}$, biotinNHCHCHalkyl), 3.12, 3.10 (each dd, each $1 \mathrm{H}, \mathrm{HN}-\mathrm{CH}_{2}-\mathrm{CH}_{2}-$ $\mathrm{CH}_{2}-\mathrm{NH}$ ), 3.09, 3.07 (each dd, each $1 \mathrm{H}, \mathrm{NH}(\mathrm{C}=\mathrm{O}) \mathrm{CH}_{2}-\mathrm{CH}_{2}-$ $\mathrm{CH}_{2}-\mathrm{CH}_{2}$-biotin), 2.66, 2.54 (each dd, each $1 \mathrm{H}, \mathrm{HN}-\mathrm{CH}_{2}-\mathrm{CH}_{2}-$ $\mathrm{CH}_{2}-\mathrm{NH}$ ), 2.11, 2.09 (each dd, each $1 \mathrm{H}, 2 \mathrm{H} \beta$-asp), 1.61, 1.58 (each dd, each $1 \mathrm{H}, \mathrm{HN}-\mathrm{CH}_{2}-\mathrm{CH}_{2}-\mathrm{CH}_{2}-\mathrm{NH}$ ), 1.52 (dd, $1 \mathrm{H}, J=$ $13.9 \mathrm{~Hz}, J=6.7 \mathrm{~Hz}, \mathrm{NH}(\mathrm{C}=\mathrm{O}) \mathrm{CH}_{2}-\mathrm{CH}_{2}-\mathrm{CH}_{2}-\mathrm{CH}$-biotin), $1.50\left(\mathrm{dd}, 1 \mathrm{H}, J=14.0 \mathrm{~Hz}, J=6.8 \mathrm{~Hz}, \mathrm{NH}(\mathrm{C}=\mathrm{O}) \mathrm{CH}_{2}-\mathrm{CH}_{2}-\right.$ $\mathrm{C} H \mathrm{H}-\mathrm{CH}_{2}$-biotin), 1.48 (dd, $1 \mathrm{H}, J=13.9 \mathrm{~Hz}, J=7.2 \mathrm{~Hz}$, $\mathrm{NH}(\mathrm{C}=\mathrm{O}) \mathrm{CH}_{2}-\mathrm{CH}_{2}-\mathrm{CH}_{2}-\mathrm{CH} H$-biotin $), 1.45(\mathrm{dd}, 1 \mathrm{H}, J=$ $14.2 \mathrm{~Hz}, J=7.0 \mathrm{~Hz}, \mathrm{NH}(\mathrm{C}=\mathrm{O}) \mathrm{CH}_{2}-\mathrm{CH}_{2}-\mathrm{CH} H-\mathrm{CH}_{2}$-biotin), 1.30, 1.27 (each dd, each $1 \mathrm{H}, \mathrm{NH}(\mathrm{C}=\mathrm{O}) \mathrm{CH}_{2}-\mathrm{CH}_{2}-\mathrm{CH}_{2}-\mathrm{CH}_{2}-$ biotin) ppm; ${ }^{13} \mathrm{C}$ NMR (150.92 MHz, $\left.\mathrm{CD}_{3} \mathrm{CN}: \mathrm{D}_{2} \mathrm{O}=1: 1\right): \delta=$ $175.93\left(\mathrm{NH}-(\mathrm{C}=\mathrm{O})_{\text {asp }}\right), 172.84\left(\mathrm{NH}-\mathrm{C}(\mathrm{O})-\left(\mathrm{CH}_{2}\right)_{4}\right.$-biotin $)$, $171.53(\mathrm{C}-\gamma), 165.08\left(\left(\mathrm{NH}_{2}\right)_{2} \mathrm{C}=\mathrm{O}\right), 157.25($ Fmoc- $\mathrm{C}=\mathrm{O})$, $144.24,144.19,129.51,128.51,128.40,127.83$ (aryl-Fmoc), 100.1 (C-1man), 73.22 (C-5man), 71.12 (C-3man), 68.07 (C-2man), 67.38 (Fmoc-CH 2 ), 67.13 (C-4man), 66.01 (C-6man), 62.25 (biotin-NHCHCHalkyl), 61.36 $\left(\mathrm{manOCH} \mathrm{CH}_{2}\right.$ ), 60.50 (biotin- $\mathrm{NHCHCH}_{2} \mathrm{~S}$ ), 57.67 (biotinNHCHCHalkyl), 52.61 (C- $\alpha$ ), 47.22 (Fmoc-CH), 39.35 (biotin$\left.\mathrm{NHCHCH}_{2} \mathrm{~S}\right), 38.36\left(\mathrm{manOCH}_{2} \mathrm{CH}_{2}\right), 37.07,36.84\left(\mathrm{HN}-\mathrm{CH}_{2}-\right.$ $\left.\mathrm{CH}_{2}-\mathrm{CH}_{2}-\mathrm{NH}\right), 35.95\left(\mathrm{C}(\mathrm{O})-\mathrm{CH}_{2}-\mathrm{CH}_{2}-\mathrm{CH}_{2}-\mathrm{CH}_{2}\right.$-biotin), 28.69 (C- $\beta$ ), $28.52\left(\mathrm{HN}-\mathrm{CH}_{2}-\mathrm{CH}_{2}-\mathrm{CH}_{2}-\mathrm{NH}\right), 28.22\left(\mathrm{C}(\mathrm{O})-\mathrm{CH}_{2}-\mathrm{CH}_{2}-\right.$ $\mathrm{CH}_{2}-\mathrm{CH}_{2}$-biotin), 25.66 (C(O)- $\mathrm{CH}_{2}-\mathrm{CH}_{2}-\mathrm{CH}_{2}-\mathrm{CH}_{2}$-biotin), $25.53\left(\mathrm{C}(\mathrm{O})-\mathrm{CH}_{2}-\mathrm{CH}_{2}-\mathrm{CH}_{2}-\mathrm{CH}_{2}\right.$-biotin) ppm.

MALDI-TOF-MS: $m / z=865.3[\mathrm{M}+\mathrm{Na}]^{+}$; ESI-MS: $m / z=$ $865.34[\mathrm{M}+\mathrm{Na}]^{+}$(842.96 calcd. for $\mathrm{C}_{40} \mathrm{H}_{54} \mathrm{~N}_{6} \mathrm{O}_{12} \mathrm{~S}$ ).
$N$-[p-(Trifluoromethyl-diazirinyl)-benzoyl]-4-[2-( $\alpha-D-$ mannopyranosyloxy)ethyl]-1-[(+)-biotinylamidopropyl]-L-aspartic acid diamide (12)

The glycoamino acid derivative $9(25.0 \mathrm{mg}, 29.7 \mu \mathrm{mol})$ was dissolved in piperidine (20\% in DMF, $3.0 \mathrm{~mL})$ and stirred at $\mathrm{RT}$ for $60 \mathrm{~min}$ to remove the Fmoc protecting group. The solvent was removed in vacuo and the resulting crude product combined with HATU $(11.3 \mathrm{mg}, 29.7 \mu \mathrm{mol})$ and the diazirine $11(7.2 \mathrm{mg}, 31.0 \mu \mathrm{mol})$, and dry DMF (1.5 mL) added under a nitrogen atmosphere. DIPEA $(0.03 \mathrm{~mL}, 87.0 \mu \mathrm{mol})$ was then added and the reaction mixture stirred overnight at RT. The solvent was removed under reduced pressure and the residue purified by flash chromatography with the exclusion of light (ethyl acetate: $\mathrm{MeOH}: \mathrm{H}_{2} \mathrm{O}=$ $6: 2: 1)$ to yield, after lyophilisation, the title compound (20.1 $\mathrm{mg}, 24.1 \mu \mathrm{mol}, 81 \%) ; R_{\mathrm{f}}=0.51 ;[\alpha]_{\mathrm{D}}{ }^{20}+23.0(c 0.12 \mathrm{mM}$, $\left.\mathrm{MeCN}: \mathrm{H}_{2} \mathrm{O}=1: 1\right)$; UV-Vis (c $0.12 \mathrm{mM}, \mathrm{MeCN}: \mathrm{H}_{2} \mathrm{O}=1: 1$ ): $\lambda_{\max }(1)=353.3 \mathrm{~nm}, \varepsilon(1)=6000 \mathrm{Lmol}^{-1} \mathrm{~cm}^{-1} ; \lambda_{\max }(2)=303.5$ $\mathrm{nm}, \varepsilon(2)=10000 \mathrm{Lmol}^{-1} \mathrm{~cm}^{-1} ; \lambda_{\max }(3)=285.2 \mathrm{~nm}, \varepsilon(3)=$ $24000 \mathrm{Lmol}^{-1} \mathrm{~cm}^{-1} ; \lambda_{\max }(4)=251.6 \mathrm{~nm}, \varepsilon(4)=37000$ $\mathrm{Lmol}^{-1} \mathrm{~cm}^{-1}$; FT-IR (KBr): $\tilde{v}=3447.5 \mathrm{~cm}^{-1}, 2928.6 \mathrm{~cm}^{-1}$, $2381.0 \mathrm{~cm}^{-1}, 1654.2 \mathrm{~cm}^{-1}, 1560.1 \mathrm{~cm}^{-1}, 1267.9 \mathrm{~cm}^{-1}$, $1136.9 \mathrm{~cm}^{-1}, 1101.9 \mathrm{~cm}^{-1}, 1059.5 \mathrm{~cm}^{-1}, 767.9 \mathrm{~cm}^{-1}$.

${ }^{1} \mathrm{H}$ NMR (600 MHz, $\left.\mathrm{CD}_{3} \mathrm{CN}: \mathrm{D}_{2} \mathrm{O}=1: 1\right): \delta=7.90(\mathrm{dt}, 2 \mathrm{H}, J=$ $8.7 \mathrm{~Hz}, J=2.0 \mathrm{~Hz}$, aryl-H), 7.39 (d, $2 \mathrm{H}, J=8.2 \mathrm{~Hz}$, aryl-H), 4.81 (dd, 1H, $J=7.7 \mathrm{~Hz}, J=6.1 \mathrm{~Hz}, \mathrm{H} \alpha$-asp), 4.75 (d, 1H, $J=$ $1.6 \mathrm{~Hz}, \mathrm{H}-1 \mathrm{man}), 4.50$ (dd, $1 \mathrm{H}, J=7.9 \mathrm{~Hz}, J=4.9 \mathrm{~Hz}$, biotin$\left.\mathrm{NH}_{2} \mathrm{CHCHalkyl}\right), 4.31$ (dd, $1 \mathrm{H}, J=7.9 \mathrm{~Hz}, J=4.5 \mathrm{~Hz}$, biotin$\mathrm{NH}_{2} \mathrm{CHCH}_{2} \mathrm{~S}$ ), 3.82 (dd, $1 \mathrm{H}, J=3.4 \mathrm{~Hz}, J=1.7 \mathrm{~Hz}, \mathrm{H}-2 \mathrm{man}$ ), $3.76\left(\mathrm{dd}, 1 \mathrm{H}, J=12.1 \mathrm{~Hz}, J=2.2 \mathrm{~Hz}, \operatorname{manOC} H \mathrm{HCH}_{2}\right), 3.69$ (dd, $1 \mathrm{H}, J=9.3 \mathrm{~Hz}, J=3.4 \mathrm{~Hz}, \mathrm{H}-3 \mathrm{man}), 3.67$ (dd, $1 \mathrm{H}, J=$ $12.0 \mathrm{~Hz}, J=2.4 \mathrm{~Hz}$, manOCH $\left.\mathrm{CCH}_{2}\right), 3.58(\mathrm{t}, 1 \mathrm{H}, J=9.8 \mathrm{~Hz}$, H-4man), 3.52 (ddd, $1 \mathrm{H}, J=9.8 \mathrm{~Hz}, J=5.3 \mathrm{~Hz}, J=2.2 \mathrm{~Hz}$, H-5man), 3.49 (dd, 1H, $J=5.5 \mathrm{~Hz}, J=4.2 \mathrm{~Hz}, \mathrm{H}-6 \mathrm{man}$ ), 3.42 (dd, $1 \mathrm{H}, J=5.7 \mathrm{~Hz}, J=2.3 \mathrm{~Hz}, \mathrm{H}-6$ 'man), 3.39 (dd, 1H, $J=$ $\left.6.7 \mathrm{~Hz}, J=12.3 \mathrm{~Hz}, \operatorname{manOCH}_{2} \mathrm{CH} H\right), 3.30(\mathrm{dd}, 1 \mathrm{H}, J=6.4 \mathrm{~Hz}$, $J=12.3 \mathrm{~Hz}$, manOCH${ }_{2} \mathrm{CHH}$ ), 3.27, 3.24 (each dd, each $1 \mathrm{H}$, $\left.\mathrm{HN}-\mathrm{CH}_{2}-\mathrm{CH}_{2}-\mathrm{CH}_{2}-\mathrm{NH}\right), 3.20(\mathrm{dd}, 1 \mathrm{H}, J=7.7 \mathrm{~Hz}, J=6.8 \mathrm{~Hz}$, biotin- $\mathrm{NH}_{2} \mathrm{CHCHalkyl}$ ), 3.13, 3.12 (each dd, each $1 \mathrm{H}$, $\mathrm{NH}(\mathrm{C}=\mathrm{O}) \mathrm{CH}_{2}-\mathrm{CH}_{2}-\mathrm{CH}_{2}-\mathrm{CH}_{2}$-biotin $), 2.91(\mathrm{dd}, 1 \mathrm{H}, J=$ $13.0 \mathrm{~Hz}, J=5.0 \mathrm{~Hz}$, biotin- $\mathrm{NH}_{2} \mathrm{CHCHHS}$ ), 2.82, 2.72 (each dd, each $\left.1 \mathrm{H}, \mathrm{HN}-\mathrm{CH}_{2}-\mathrm{CH}_{2}-\mathrm{CH}_{2}-\mathrm{NH}\right), 2.70(\mathrm{dd}, 1 \mathrm{H}, J=13.1 \mathrm{~Hz}, J$ $=6.4 \mathrm{~Hz}$, biotin- $\mathrm{NH}_{2} \mathrm{CHCH} H \mathrm{~S}$ ), 2.16, 2.15 (each dd, each $1 \mathrm{H}$, $\mathrm{NH}(\mathrm{C}=\mathrm{O}) \mathrm{CH}_{2}-\mathrm{CH}_{2}-\mathrm{CH}_{2}-\mathrm{CH}_{2}$-biotin), 1.68, 1.67 (each dd, each $1 \mathrm{H}, \mathrm{NH}(\mathrm{C}=\mathrm{O}) \mathrm{CH}_{2}-\mathrm{CH}_{2}-\mathrm{CH}_{2}-\mathrm{CH}_{2}$-biotin), 1.63 (dd, $1 \mathrm{H}, J=$ $13.3 \mathrm{~Hz}, J=6.7 \mathrm{~Hz}, \mathrm{NH}(\mathrm{C}=\mathrm{O}) \mathrm{CH}_{2}-\mathrm{CH} \mathrm{H}-\mathrm{CH}_{2}-\mathrm{CH}_{2}$-biotin), $1.57\left(\mathrm{dd}, 1 \mathrm{H}, J=15.1 \mathrm{~Hz}, J=7.4 \mathrm{~Hz}, \mathrm{HN}-\mathrm{CH}_{2}-\mathrm{CH}-\mathrm{CH}_{2}-\right.$ $\mathrm{NH}), 1.53\left(\mathrm{dd}, 1 \mathrm{H}, J=13.1 \mathrm{~Hz}, J=6.9 \mathrm{~Hz}, \mathrm{NH}(\mathrm{C}=\mathrm{O}) \mathrm{CH}_{2-}\right.$ $\mathrm{CH} H-\mathrm{CH}_{2}-\mathrm{CH}_{2}$-biotin), 1.51 (dd, $1 \mathrm{H}, J=13.9 \mathrm{~Hz}, J=6.8 \mathrm{~Hz}$, $\mathrm{H} \beta$-asp), 1.36 (dd, $1 \mathrm{H}, J=15.5 \mathrm{~Hz}, J=7.2 \mathrm{~Hz}, \mathrm{HN}-\mathrm{CH}_{2}-\mathrm{CH} H$ - 
$\mathrm{CH}_{2}-\mathrm{NH}$ ), 1.30 (dd, $1 \mathrm{H}, J=13.4 \mathrm{~Hz}, J=6.9 \mathrm{~Hz}, \mathrm{H} \beta$ '-asp) ppm; ${ }^{13} \mathrm{C}$ NMR $\left(150.90 \mathrm{MHz}, \mathrm{CD}_{3} \mathrm{CN}: \mathrm{D}_{2} \mathrm{O}=1: 1\right): \delta=176.60$ (aryl$\mathrm{C}=\mathrm{O}), 172.78\left(\mathrm{NH}-(\mathrm{C}=\mathrm{O})_{\mathrm{asp}}\right), 172.37(\mathrm{C}-\gamma), 168.61(\mathrm{NH}-\mathrm{C}(\mathrm{O})-$ $\mathrm{CH}_{2}-\left(\mathrm{CH}_{2}\right)_{3}$-biotin), $165.66\left(\left(\mathrm{NH}_{2}\right)_{2} \mathrm{C}=\mathrm{O}\right), 135.57,133.14$, 129.11, 127.73 (aryl-C), 124.44 (q, $\left.J_{C, F}=\mathrm{Hz}, \mathrm{CF}_{3}\right), 100.72$ (C-1man), $87.77\left(\mathrm{~N}=\mathrm{N}-\mathrm{CCF}_{3}\right) 73.82(\mathrm{C}-5 \mathrm{man}), 71.68$ (C-3man), 71.10 (C-2man), 67.70 (C-4man), 66.73 (C-6man), 62.81 (biotin- $\left.\mathrm{NH}_{2} \mathrm{CHCHalkyl}\right), 61.95\left(\mathrm{manOCH} \mathrm{CH}_{2}\right), 61.09$ (biotin- $\mathrm{NH}_{2} \mathrm{CHCH}_{2} \mathrm{~S}$ ), 56.29 (biotin- $\mathrm{NH}_{2} \mathrm{CHCHalkyl),} 52.36$ (C- $\alpha$ ), 40.78 (biotin- $\mathrm{NH}_{2} \mathrm{CHCH}_{2} \mathrm{~S}$ ), 39.89 (manOCH $\mathrm{CH}_{2}$ ), $38.13\left(\mathrm{HN}-\mathrm{CH}_{2}-\mathrm{CH}_{2}-\mathrm{CH}_{2}-\mathrm{NH}\right), 37.68\left(\mathrm{HN}-\mathrm{CH}_{2}-\mathrm{CH}_{2}-\mathrm{CH}_{2}-\right.$ $\mathrm{NH}), 37.36\left(\mathrm{NH}-\mathrm{C}(\mathrm{O})-\mathrm{CH}_{2}-\left(\mathrm{CH}_{2}\right)_{3}\right.$-biotin), 36.49 (C- $\left.\beta\right), 29.71$ $\left(\mathrm{HN}-\mathrm{CH}_{2}-\mathrm{CH}_{2}-\mathrm{CH}_{2}-\mathrm{NH}\right), 29.24\left(\mathrm{NH}-\mathrm{C}(\mathrm{O})-\left(\mathrm{CH}_{2}\right)_{3}-\mathrm{CH}_{2}-\right.$ biotin), 28.78 ( $\mathrm{NH}-\mathrm{C}(\mathrm{O})-\mathrm{CH}_{2}-\mathrm{CH}_{2}-\mathrm{CH}_{2}-\mathrm{CH}_{2}$-biotin), 26.24 (NH-C(O)- $\mathrm{CH}_{2}-\mathrm{CH}_{2}-\mathrm{CH}_{2}-\mathrm{CH}_{2}$-biotin) ppm.

MALDI-TOF-MS: $m / z=827.3\left[\mathrm{M}-\mathrm{N}_{2}+\mathrm{Na}\right]^{+}$; ESI-MS: $m / z=$ $855.29[\mathrm{M}+\mathrm{Na}]^{+}, 827.29\left[\mathrm{M}-\mathrm{N}_{2}+\mathrm{Na}\right]^{+}(832.85$ calcd. for $\mathrm{C}_{34} \mathrm{H}_{47} \mathrm{~F}_{3} \mathrm{~N}_{8} \mathrm{O}_{11} \mathrm{~S}$ ).

\section{$N$-[p-(Trifluoromethyl-diazirinyl)-benzoyl]-4-[(+)- biotinylamidopropyl]-1-[2-( $\alpha$-D-mannopyranosyloxy)- ethyl]-L-aspartic acid diamide (13)}

The glycoamino acid derivative $\mathbf{1 0}(19.6 \mathrm{mg}, 23.2 \mu \mathrm{mol})$ was dissolved in piperidine (20\% in DMF, $1.5 \mathrm{~mL})$ and stirred at $\mathrm{RT}$ for $60 \mathrm{~min}$ to remove the Fmoc protecting group. The solvent was removed in vacuo and the resulting crude product combined with HATU $(14.0 \mathrm{mg}, 36.8 \mu \mathrm{mol})$ and the diazirine $11(7.2 \mathrm{mg}, 30.9 \mu \mathrm{mol})$, and dry DMF $(1.5 \mathrm{~mL})$ added under a nitrogen atmosphere. DIPEA $(0.05 \mathrm{~mL}, 145 \mu \mathrm{mol})$ was then added and the reaction mixture stirred overnight at RT. The solvent was removed under reduced pressure and the residue purified by flash chromatography with the exclusion of light (ethyl acetate: $\mathrm{MeOH}: \mathrm{H}_{2} \mathrm{O}=$ $6: 2: 1$ ) to yield, after lyophilisation, the title compound (19 mg, $22.8 \mu \mathrm{mol}, 98 \%) ; R_{\mathrm{f}}=0.33 ;[\alpha]_{\mathrm{D}}{ }^{20}+30.0(c \quad 0.12 \mathrm{mM}$, $\left.\mathrm{MeCN}: \mathrm{H}_{2} \mathrm{O}=1: 1\right)$; UV-Vis (c $\left.0.12 \mathrm{mM}, \mathrm{MeCN}: \mathrm{H}_{2} \mathrm{O}=1: 1\right)$ : $\lambda_{\max }(1)=335.9 \mathrm{~nm}, \varepsilon(1)=9833.3 \mathrm{Lmol}^{-1} \mathrm{~cm}^{-1} ; \lambda_{\max }(2)=$ $278.2 \mathrm{~nm}, \varepsilon(2)=18333.3 \mathrm{Lmol}^{-1} \mathrm{~cm}^{-1} ; \lambda_{\max }(3)=233.5 \mathrm{~nm}$, $\varepsilon(3)=23333.3 \mathrm{Lmol}^{-1} \mathrm{~cm}^{-1}$; FT-IR $(\mathrm{KBr}): \tilde{v}=3447.7 \mathrm{~cm}^{-1}$, $2940.5 \mathrm{~cm}^{-1}, 2380.9 \mathrm{~cm}^{-1}, 1684.7 \mathrm{~cm}^{-1}, 1654.2 \mathrm{~cm}^{-1}$, $1636.6 \mathrm{~cm}^{-1}, 1560.1 \mathrm{~cm}^{-1}, 1438.3 \mathrm{~cm}^{-1}, 1400.2 \mathrm{~cm}^{-1}$, $1279.8 \mathrm{~cm}^{-1}, 1202.4 \mathrm{~cm}^{-1}, 1113.1 \mathrm{~cm}^{-1}, 761.9 \mathrm{~cm}^{-1}$.

${ }^{1} \mathrm{H}$ NMR (600 MHz, $\left.\mathrm{CD}_{3} \mathrm{CN}-\mathrm{D}_{2} \mathrm{O}, 1: 1\right): \delta=8.23(\mathrm{dd}, 2 \mathrm{H}, J=$ $8.5 \mathrm{~Hz}, J=1.4 \mathrm{~Hz}$, aryl-H), $7.38(\mathrm{dd}, 2 \mathrm{H}, J=8.8 \mathrm{~Hz}, J=$ $1.3 \mathrm{~Hz}$, aryl-H), 4.86 (dd, $1 \mathrm{H}, J=8.6 \mathrm{~Hz}, J=5.3 \mathrm{~Hz}, \mathrm{H} \alpha$-asp), 4.76 (d, 1H, $J=1.5 \mathrm{~Hz}, \mathrm{H}-1 \mathrm{man}), 4.49$ (dd, $1 \mathrm{H}, J=7.7 \mathrm{~Hz}, J=$ $4.4 \mathrm{~Hz}$, biotin-NHCHCH $\left.\mathrm{NH}_{2} \mathrm{~S}\right), 4.30(\mathrm{dd}, 1 \mathrm{H}, J=8.0 \mathrm{~Hz}, J=$ $4.4 \mathrm{~Hz}$, biotin-NHCHCHalkyl), $3.80(\mathrm{dd}, 1 \mathrm{H}, J=3.3 \mathrm{~Hz}, J=$ $1.7 \mathrm{~Hz}, \mathrm{H}-2 \mathrm{man}), 3.73(\mathrm{dd}, 1 \mathrm{H}, J=12.2 \mathrm{~Hz}, J=2.3 \mathrm{~Hz}$,
$\left.\operatorname{manOCH} \mathrm{HCH}_{2}\right), 3.69(\mathrm{dd}, 1 \mathrm{H}, J=11.0 \mathrm{~Hz}, J=4.3 \mathrm{~Hz}$, H-6man), 3.68 (dd, 1H, $J=9.7 \mathrm{~Hz}, J=3.2 \mathrm{~Hz}, \mathrm{H}-3 \operatorname{man}$ ), 3.66 (dd, $\left.1 \mathrm{H}, J=12.2 \mathrm{~Hz}, J=3.3 \mathrm{~Hz}, \operatorname{manOCH} \mathrm{CCH}_{2}\right), 3.59$ (t, $1 \mathrm{H}$, $J=9.8 \mathrm{~Hz}, \mathrm{H}-4 \mathrm{man}), 3.52(\mathrm{dd}, 1 \mathrm{H}, J=10.6 \mathrm{~Hz}, J=4.4 \mathrm{~Hz}$, H-6'man), 3.49 (dd, 1H, $J=10.0 \mathrm{~Hz}, J=4.1 \mathrm{~Hz}, \mathrm{H}-5 \mathrm{man}$ ), 3.44 $\left(\mathrm{dd}, 1 \mathrm{H}, J=6.8 \mathrm{~Hz}, J=4.1 \mathrm{~Hz}, \operatorname{manOCH}_{2} \mathrm{CHH}\right), 3.32(\mathrm{dd}, 1 \mathrm{H}$, $\left.J=6.1 \mathrm{~Hz}, J=4.0 \mathrm{~Hz}, \operatorname{manOCH}_{2} \mathrm{CH} H\right), 3.20(\mathrm{dd}, 1 \mathrm{H}, J=$ $8.8 \mathrm{~Hz}, J=5.4 \mathrm{~Hz}$, biotin-NHCHCHalkyl), 3.19 (dd, $1 \mathrm{H}, J=$ 13.7 Hz, $J=6.9 \mathrm{~Hz}, \mathrm{HN}-\mathrm{CHH}-\mathrm{CH}_{2}-\mathrm{CH}_{2}-\mathrm{NH}$ ), 3.16, 3.10 (each dd, each $1 \mathrm{H}, \mathrm{NH}(\mathrm{C}=\mathrm{O}) \mathrm{CH}_{2}-\mathrm{CH}_{2}-\mathrm{CH}_{2}-\mathrm{CH}_{2}$-biotin), 3.05 (dd, $1 \mathrm{H} J=13.4 \mathrm{~Hz}, J=7.0 \mathrm{~Hz}, \mathrm{HN}-\mathrm{CH} H-\mathrm{CH}_{2}-\mathrm{CH}_{2}-\mathrm{NH}$ ), 2.90 (dd, $1 \mathrm{H}, J=13.0 \mathrm{~Hz}, J=5.1 \mathrm{~Hz}$, biotin-NHCHCHHS$), 2.77$ (dd, $\left.1 \mathrm{H}, J=14.7 \mathrm{~Hz}, J=5.3 \mathrm{~Hz}, \mathrm{HN}-\mathrm{CH}_{2}-\mathrm{CH}_{2}-\mathrm{CHH}-\mathrm{NH}\right), 2.69$ (dd, $1 \mathrm{H}, J=12.6 \mathrm{~Hz}, J=4.8 \mathrm{~Hz}$, biotin-NHCHCHHS), 2.68 (dd, $1, J=14.9 \mathrm{~Hz}, J=5.8 \mathrm{~Hz}, \mathrm{HN}-\mathrm{CH}_{2}-\mathrm{CH}_{2}-\mathrm{CH} H-\mathrm{NH}$ ), 2.16 (dd, $1 \mathrm{H}, J=15.3 \mathrm{~Hz}, J=7.7 \mathrm{~Hz}, \mathrm{H} \beta$-asp), 2.12 (dd, 1H, $J=$ $14.9 \mathrm{~Hz}, J=7.5 \mathrm{~Hz}, \mathrm{H} \beta$ '-asp), 1.66 (ddd, $1 \mathrm{H}, J=13.8 \mathrm{~Hz}, J=$ $7.1 \mathrm{~Hz}, J=6.2 \mathrm{~Hz}, \mathrm{NH}(\mathrm{C}=\mathrm{O}) \mathrm{CH}_{2}-\mathrm{CH} H-\mathrm{CH}_{2}-\mathrm{CH}_{2}$-biotin $), 1.64$ $\left(\mathrm{dd}, 1 \mathrm{H}, J=15.3 \mathrm{~Hz}, J=6.2 \mathrm{~Hz}, \mathrm{NH}(\mathrm{C}=\mathrm{O}) \mathrm{CH}_{2}-\mathrm{CH}_{2}-\mathrm{CH} H-\right.$ $\mathrm{CH}_{2}$-biotin), 1.57 (ddd, $1 \mathrm{H}, J=13.3 \mathrm{~Hz}, J=6.8 \mathrm{~Hz}, J=6.3 \mathrm{~Hz}$, $\mathrm{NH}(\mathrm{C}=\mathrm{O}) \mathrm{CH}_{2}-\mathrm{CH} \mathrm{H}-\mathrm{CH}_{2}-\mathrm{CH}_{2}$-biotin $), 1.55(\mathrm{dd}, 1 \mathrm{H}, J=$ $15.5 \mathrm{~Hz}, J=6.8 \mathrm{~Hz}, \mathrm{NH}(\mathrm{C}=\mathrm{O}) \mathrm{CH}_{2}-\mathrm{CH}_{2}-\mathrm{CHH}-\mathrm{CH}_{2}$-biotin), 1.53, 1.52 (each dd, each $1 \mathrm{H}, \mathrm{NH}(\mathrm{C}=\mathrm{O}) \mathrm{CH}_{2}-\mathrm{CH}_{2}-\mathrm{CH}_{2}-\mathrm{CH}_{2}-$ biotin), 1.34, 1.27 (each dd, each $1 \mathrm{H}, J=15.3 \mathrm{~Hz}, J=7.0 \mathrm{~Hz}$, $\left.\mathrm{HN}-\mathrm{CH}_{2}-\mathrm{CH}_{2}-\mathrm{CH}_{2}-\mathrm{NH}\right) \mathrm{ppm} ;{ }^{13} \mathrm{C} \mathrm{NMR}(150.90 \mathrm{MHz}$, $\left.\mathrm{CD}_{3} \mathrm{CN}: \mathrm{D}_{2} \mathrm{O}=1: 1\right): \delta=176.86(\mathrm{C}-\gamma), 172.58\left(\mathrm{NH}-(\mathrm{C}=\mathrm{O})_{\mathrm{asp}}\right)$, $171.47\left(\mathrm{NH}(\mathrm{C}=\mathrm{O})-\left(\mathrm{CH}_{2}\right)_{4}\right.$-biotin $), 168.28($ aryl-C=O), 165.16 $\left(\left(\mathrm{NH}_{2}\right)_{2} \mathrm{C}=\mathrm{O}\right), 149.11,139.43$ (aryl-C), $136.19\left(\mathrm{q}, J_{C, F}=\mathrm{Hz}\right.$, $\left.\mathrm{CF}_{3}\right), 129.08,128.99$ (aryl-C), $100.67(\mathrm{C}-1 \mathrm{man}), 84.21(\mathrm{~N}=\mathrm{N}-$ $\mathrm{CCF}_{3}$ ), 73.78 (C-5man), 71.69 (C-2man), 71.12 (C-3man), 67.74 (C-4man), 66.57 (C-6man), 62.85 (biotinNHCHCHalkyl), $61.92\left(\right.$ manOC $\left.\mathrm{H}_{2} \mathrm{CH}_{2}\right), 61.09$ (biotin$\mathrm{NHCHCH}_{2} \mathrm{~S}$ ), 56.32 (biotin-NHCHCHalkyl), 52.34 (C- $\alpha$ ), 40.78 (biotin- $\left.\mathrm{NHCHCH}_{2} \mathrm{~S}\right), 39.97\left(\mathrm{manOCH}_{2} \mathrm{CH}_{2}\right), 38.47$, $37.63\left(\mathrm{HN}-\mathrm{CH}_{2}-\mathrm{CH}_{2}-\mathrm{CH}_{2}-\mathrm{NH}\right), 37.39\left(\mathrm{NH}(\mathrm{C}=\mathrm{O}) \mathrm{CH}_{2}-\left(\mathrm{CH}_{2}\right)_{3}-\right.$ biotin), 36.50 (C- $\beta$ ), 29.21 (C- $\left.\mathrm{HN}-\mathrm{CH}_{2}-\mathrm{CH}_{2}-\mathrm{CH}_{2}-\mathrm{NH}\right), 29.08$ $\left(\mathrm{NH}(\mathrm{C}=\mathrm{O})-\left(\mathrm{CH}_{2}\right)_{3}-\mathrm{CH}_{2}\right.$-biotin), 28.79, $26.23\left(\mathrm{NH}(\mathrm{C}=\mathrm{O})-\mathrm{CH}_{2}-\right.$ $\mathrm{CH}_{2}-\mathrm{CH}_{2}-\mathrm{CH}_{2}$-biotin) ppm.

MALDI-TOF-MS: $m / z=855.3[\mathrm{M}+\mathrm{Na}]^{+}$; ESI-MS: $\mathrm{m} / z=$ $827.31\left[\mathrm{M}-\mathrm{N}_{2}+\mathrm{Na}\right]^{+}$; $855.31[\mathrm{M}+\mathrm{Na}]^{+}$(832.85 calcd. for $\left.\mathrm{C}_{34} \mathrm{H}_{47} \mathrm{~F}_{3} \mathrm{~N}_{8} \mathrm{O}_{11} \mathrm{~S}\right)$.

\section{Acknowledgements}

We are thankful to PD Dr. Buko Lindner (Research Center Borstel, Center for Medicine and Biosciences) and Prof. Dr. Matthias Leippe and Dr. Christoph Gelhaus (Zoological Institute at CAU) for making the MS analysis of photo-crosslinked products possible, and to Christiana Albertina University (CAU) for financial support. 


\section{References}

1. Kotzyba-Hilbert, F.; Kapfer, I.; Goeldner, M. Angew. Chem., Int. Ed. Engl. 1995, 34, 1296-1312. doi:10.1002/anie.199512961 Angew. Chem. 1995, 107, 1391-1408. doi:10.1002/ange.19951071204

2. Lindhorst, T. K.; Bruegge, K.; Fuchs, A.; Sperling, $O$ Beilstein J. Org. Chem. 2010, 6, 801-809. doi:10.3762/bjoc.6.90

3. Ohlsen, K.; Oelschlaeger, T. A.; Hacker, J.; Khan, A. S. Top. Curr. Chem. 2009, 288, 109-120. doi:10.1007/128_2008_10

4. Klemm, P.; Schembri, M. Int. J. Med. Microbiol. 2000, 290, 27-35.

5. Mulvey, M. A. Cell. Microbiol. 2002, 4, 257-271. doi:10.1046/j.1462-5822.2002.00193.x

6. Choudhury, D.; Thompson, A.; Stojanoff, V.; Langerman, S.; Pinkner, J.; Hultgren, S. J.; Knight, S. D. Science 1999, 285, 1061-1066. doi:10.1126/science.285.5430.1061

7. Hung, C.-S.; Bouckaert, J.; Hung, D.; Pinkner, J.; Widberg, C.; DeFusco, A.; Auguste, C. G.; Strouse, R.; Langermann, S.; Waksman, G.; Hultgren, S. J. Mol. Microbiol. 2002, 44, 903-915. doi:10.1046/j.1365-2958.2002.02915.x

8. Bouckaert, J.; Berglund, J.; Schembri, M.; De Genst, E.; Cools, L.; Wuhrer, M.; Hung, C.-S.; Pinkner, J.; Slättegård, R.; Zavialov, A.; Choudhury, D.; Langermann, S.; Hultgren, S. J.; Wyns, L.; Klemm, P.; Oscarson, S.; Knight, S. D.; De Greve, H. Mol. Microbiol. 2005, 55, 441-455. doi:10.1111/j.1365-2958.2004.04415.x

9. Firon, N.; Ashkenazi, S.; Mirelman, D.; Ofek, I.; Sharon, N. Infect. Immun. 1987, 55, 472-476.

10. Lindhorst, T. K.; Kieburg, C.; Krallmann-Wenzel, U. Glycoconjugate J. 1998, 15, 605-613. doi:10.1023/A:1006920027641

11. Röckendorf, N.; Sperling, O.; Lindhorst, T. K. Aust. J. Chem. 2002, 55, 87-93. doi:10.1071/CH02025

12. Lahmann, M. Top. Curr. Chem. 2009, 288, 17-65. doi:10.1007/128_2008_30

13. Chabre, Y. M.; Roy, R. Adv. Carbohydr. Chem. Biochem. 2010, 63, 165-393. doi:10.1016/S0065-2318(10)63006-5

14. Knight, S. D.; Bouckaert, J. Top. Curr. Chem. 2009, 288, 67-107. doi:10.1007/128_2008_13

15. Wiegand, M.; Lindhorst, T. K. Eur. J. Org. Chem. 2006, 4841-4851. doi:10.1002/ejoc.200600449

16. Hashimoto, M.; Hatanaka, Y. Eur. J. Org. Chem. 2008, 2513-2523. doi:10.1002/ejoc.200701069

17. Rarey, M.; Kramer, B.; Lengauer, T.; Klebe, G. J. Mol. Biol. 1996, 261, 470-489. doi:10.1006/jmbi.1996.0477

18. Rarey, M.; Kramer, B.; Lengauer, T. J. Comput.-Aided Mol. Des. 1997, 11, 369-384. doi:10.1023/A:1007913026166

19. Kramer, B.; Rarey, M.; Lengauer, T. Proteins: Struct., Funct., Genet. 1999, 37, 228-241.

doi:10.1002/(SICI)1097-0134(19991101)37:2<228::AID-PROT8>3.0.C $0 ; 2-8$

20. Sperling, O.; Fuchs, A.; Lindhorst, T. K. Org. Biomol. Chem. 2006, 4, 3913-3922. doi:10.1039/b610745a

21. Kötter, S.; Krallmann-Wenzel, U.; Ehlers, S.; Lindhorst, T. K. J. Chem. Soc., Perkin Trans. 1 1998, 2193-2200. doi:10.1039/a801985a

22. Dubber, M.; Sperling, O.; Lindhorst, T. K. Org. Biomol. Chem. 2006, 4, 3901-3912. doi:10.1039/b610741a

23. Kleinert, M.; Röckendorf, N.; Lindhorst, T. K. Eur. J. Org. Chem. 2004, 3931-3940. doi:10.1002/ejoc.200400239
24. Jones, C. H.; Pinkner, J. S.; Roth, R.; Heuser, J.; Nicholes, A. V.; Abraham, S. N.; Hultgren, S. J. Proc. Natl. Acad. Sci. U. S. A. 1995, 92, 2081-2085. doi:10.1073/pnas.92.6.2081

25. Biemann, K. Methods Enzymol. 1990, 193, 886-887. doi:10.1016/0076-6879(90)93460-3

\section{License and Terms}

This is an Open Access article under the terms of the Creative Commons Attribution License

(http://creativecommons.org/licenses/by/2.0), which permits unrestricted use, distribution, and reproduction in any medium, provided the original work is properly cited.

The license is subject to the Beilstein Journal of Organic Chemistry terms and conditions:

(http://www.beilstein-journals.org/bjoc)

The definitive version of this article is the electronic one which can be found at: doi:10.3762/bjoc.6.91 